\title{
A decadally-resolved paleohurricane record archived in the late Holocene sediments of a Florida sinkhole
}

\author{
Philip Lane $\mathrm{a}^{\mathrm{a}^{*}}$ \\ plane@mit.edu
}

Jeffrey P. Donnelly ${ }^{\text {a }}$

jdonnelly@whoi.edu

\author{
Jonathan D. Woodruff ${ }^{\text {b }}$ \\ woodruff@geo.umass.edu
}

\begin{abstract}
Andrea D. Hawkes a
ahawkes@whoi.edu

${ }^{a}$ Woods Hole Oceanographic Institution, Department of Marine Geology and Geophysics, MS \# 22

Woods Hole, MA, 02543, U.S.A.

${ }^{b}$ University of Massachusetts at Amherst, Department of Geosciences, 249 Morrill Science Center, 611 North Pleasant St., Amherst, MA, 01003, U.S.A.
\end{abstract}

\begin{abstract}
A 4500-year record of hurricane-induced storm surges is developed from sediment cores collected from a coastal sinkhole near Apalachee Bay, Florida. Recent deposition of sand layers in the upper sediments of the pond was found to be contemporaneous with significant, historic storm surges at the site modeled using SLOSH and the Best Track, post-1851 A.D. dataset. Using the historic portion of the record for calibration, paleohurricane deposits were identified by sand content and dated using radiocarbon-based age models. Marine-indicative foraminifera, some originating at least $5 \mathrm{~km}$ offshore, were present in several modern and ancient storm deposits. The presence and long-term preservation of offshore foraminifera suggest that this site and others like it may yield promising microfossil-based paleohurricane reconstructions in the future. Due to the sub-decadal ( 7 year) resolution of the record and the site's high susceptibility to hurricane-generated storm surges, the average, local frequency of recorded events, approximately 3.9 storms per century, is greater than that of previously published paleohurricane records from the region. The high incidence of recorded events permitted a time series of local hurricane frequency during the last five millennia to be constructed. Variability in the frequency of the largest storm layers was found to be greater than what would likely occur by chance alone, with intervals of both anomalously high and low storm frequency identified. However, the rate at which smaller layers were deposited was relatively constant over the last

* Corresponding author address: Philip Lane, Massachusetts Institute of Technology / Woods Hole Oceanographic Institution Joint Program, Department of Marine Geology and Geophysics, 360 Woods Hole Rd., MS \# 22, Woods Hole, MA 02543, U.S.A. Phone: 1-(617)-800-3516; Fax: 1-(508)-457-2187; E-mail: plane@mit.edu
\end{abstract}


five millennia. This may suggest that significant variability in hurricane frequency has occurred only in the highest magnitude events. The frequency of high magnitude events peaked near 6 storms per century between 2800 and 2300 years ago. High magnitude events were relatively rare with about 0-3 storms per century occurring between 1900 to 1600 years ago and between 400 to 150 years ago. A marked decline in the number of large storm deposits, which began around 600 years ago, has persisted through present with below average frequency over the last 150 years when compared to the preceding five millennia.

Key Words: Paleotempestology; paleohurricane; hurricane; tropical cyclone; sinkhole; storm surge; SLOSH; Gulf of Mexico; Apalachee Bay; Holocene

\section{Introduction}

\subsection{Review and Motivation}

The manner in which tropical cyclone activity and climate interact has critical implications for society and is not well understood. Meteorological records of the number, track and intensity of hurricanes in the Atlantic extend back to the mid- $19^{\text {th }}$ century, although debate exists over whether trends in storm observations genuinely reflect secular changes in the underlying population of Atlantic hurricanes or if advances in storm detection and observation prevent the attribution of these trends to changes in storm climate (Goldenberg et al. 2001, Emanuel 2005, Webster et al. 2005, Anthes et al. 2006, Hoyos et al. 2006, Mann and Emanuel 2006, Trenberth and Shea 2006, Chang and Guo 2007, Holland and Webster 2007, Kossin et al. 2007, Landsea 2007, Mann et al. 2007, Elsner et al. 2008, Chen et al. 2009). Moreover, the brief observational record is inadequate for characterizing natural variability in hurricane activity occurring on longer than multi-decadal timescales.

In an effort to extend the hurricane record further into the past, a number of paleohurricane proxies are being developed. These proxies can be categorized into two main types: isotope-based proxies that rely on the detection of tropical cyclone rainfall signatures preserved in corals (Cohen 2001, Hetzinger et al. 2008), tree rings (Miller et al. 2006), and speleothems (Frappier et al. 2007, Nott et al. 2007), and sediment-based proxies such as cyclone surge-constructed beach ridges (Nott and Hayne 2001, Nott et al. 2009) and overwash deposits preserved in back barrier lagoons (Donnelly 2005, Donnelly and Woodruff 2007, Woodruff et al. 2008a, Woodruff et al. 2008b, Wallace and Anderson 2010), coastal lakes (Liu and Fearn 1993, Liu and Fearn 2000, Liu and Fearn 2002, Lambert et al. 2003, Lambert et al. 2008), and marshes (Donnelly et al. 2001a, Donnelly et al. 2001b, Donnelly et al. 2004, Scileppi and Donnelly 2007, Boldt et al. 2010). Isotope-based proxies have in some cases provided exceptional, sub-annual resolution; however, such records often span only a relatively short interval of time. While sediment-based proxies have yielded much longer records reaching back several millennia, low sediment accumulation rates and high flooding thresholds at most sites studied have resulted in low resolution records of high magnitude events. For these reasons, paleohurricane frequency in existing sediment records has usually averaged less than one storm per century. Such low probabilities of occurrence make it difficult to differentiate significant changes in storm climate affecting a site from the random, temporal clustering of events that could result merely from the stochastic nature of hurricane landfalls at any particular location. 
In this study, we develop a 4500-year record of hurricane storm surges impacting Bald Point, Florida. The record, developed from the sedimentary archive preserved in a coastal sinkhole, provides sub-decadal resolution and is the first produced from this type of depositional environment. The average event frequency of 3.9 storms per century, greater than that of any published paleohurricane record, permitted the objective identification of intervals with significantly elevated storm frequency as well as abnormally inactive periods in the Northeastern Gulf of Mexico during the last half of the Holocene.

\subsection{Study Area}

Apalachee Bay, situated in the Big Bend region of Florida's Gulf Coast, encompasses $400 \mathrm{~km}^{2}$ of the coastal shelf submerged to an average depth of 3 meters (USEPA 1999) (Figure 1a,b). This shallow, concave bay is highly susceptible to extreme storm surges generated by hurricanes that frequent the Gulf of Mexico. Storm tide frequency analysis by a joint probability method suggests that the expected 100-yr still water level surge in the bay is about 4.5 meters above mean sea level (Ho and Tracey 1975). Storm surges in excess of 4 meters have been observed in the area (Ludlum 1963, Case 1986), and inundation modeling indicates that surges exceeding 8 meters, which would penetrate tens of kilometers inland, can occur under plausible storm conditions (Jelesnianski et al. 1992).

Bald Point, a roughly $40-\mathrm{km}^{2}$ peninsula adjoining Ochlokonee Bay to the north and Apalachee Bay to the east and south (Figure 1b), is perforated by dozens of sinkholes. The local landscape rests on hundreds of meters of underlying limestone and dolomite, which is overlain by a veneer of clastic sand and clays that, in turn, is covered by a layer of fine quartz sand ten to sixty meters thick (Puri and Vernon 1964, Sinclair and Stewart 1985). The $\mathrm{pH}$ of meteoric water is lowered by its contact with the atmosphere and organics in the soil, and the acidity of the resulting groundwater erodes the underlying limestone (Lane 1986). The resulting subterranean dissolution causes sinkhole formation either through the gradual, local subsidence of the ground, thereby forming a cover-subsidence sinkhole, or by the sudden, catastrophic failure of an underground cavity, resulting in a cover-collapse sinkhole. The character of the overlying sediments determines the type of sinkhole that forms. On Bald Point, where the overlying clays and sands are thick and cohesive enough to temporarily support the ground surface above a cavity, most sinkholes are of the cover-collapse variety (Sinclair and Stewart 1985). Once formed, the sinkholes begin to fill with sediments that preserve valuable paleoenvironmental and climatic records (Watts et al. 1992, Watts and Hansen 1994, Kindinger et al. 1999, Hodell et al. 2005, Zarikian et al. 2005).

Sediment cores used to develop this study's paleohurricane record were collected from Mullet Pond $\left(29^{\circ} 55.520^{\prime} \mathrm{N}, 84^{\circ} 20.275^{\prime} \mathrm{W}\right)$, a nearly circular, $200 \mathrm{~m}$ diameter cover-collapse sinkhole located on Bald Point. The pond is $350 \mathrm{~m}$ from Apalachee Bay and is separated from the bay by a $3-4 \mathrm{~m}$ high (NAVD88) dune ridge $200 \mathrm{~m}$ to the east (Figure 1c). The local landscape west of the dune ridge has a relatively flat 2 to $3 \mathrm{~m}$ (NAVD88) elevation and, owing to the sandy soils that limit runoff during rain events (Puri and Vernon 1964), freshwater stream and river systems are absent (Figure 1c). A tidal creek running through a small salt marsh to the north intermittently connects Mullet Pond to the open coast (Figure 1c) where the local mean tidal range is about $0.70 \mathrm{~m}$ (NOAA 2010a). When field work was conducted in January of 2008, the pond had a maximum water depth of $2.3 \mathrm{~m}$ and an average surface salinity of $10 \mathrm{psu}$. 


\section{Methods}

\subsection{Field work}

A portable Edgetech $31004-24 \mathrm{kHz}$ sonar was used to map the bathymetry and image the sub-bottom stratigraphy of Mullet Pond, and the resulting data guided the selection of coring locations. Four sediment cores were collected along a transect, with two long $(\sim 6 \mathrm{~m})$ cores (hereafter MLT1 and MLT2) retrieved from the deep, central portion of the pond and two short $(\sim 2 \mathrm{~m})$ cores collected nearer to the pond's eastern shore (Figure 1c). A piston corer was used to capture surface drives in 3" polycarbonate barrels, while deeper drives were collected in 3" aluminum vibracores. Laboratory analyses focused on the two $\sim 6 \mathrm{~m}$ cores (MLT1 and MLT2) retrieved from the central portion of the pond in water depths of 2.3 and $2.2 \mathrm{~m}$, respectively. These cores were taken in regions where the sub-bottom stratigraphy indicated the deepest reservoirs of lacustrine sediments (Figure 2a,b). Twenty-seven surface sediment samples (top 1 $\mathrm{cm}$ ) were collected near the pond, dune ridge, beach, near-shore and offshore environments down to water depths of $14 \mathrm{~m}$ up to $20 \mathrm{~km}$ offshore. Marine samples were collected along three shore-normal depth transects: one in Ochlokonee Bay and two in the Gulf beginning 12 and 16 $\mathrm{km}$ west of Mullet Pond (Table 1). A handheld GPS unit provided the coordinates of coring and surface sample locations, and salinities were measured with an optical diffraction salinity meter.

\subsection{Age control}

To develop age models for MLT1 and MLT2, plant and wood fragments were collected, cleaned, dried and sent to the National Ocean Sciences AMS facility at Woods Hole Oceanographic Institution for radiocarbon dating. Calendar ages (in years before present, where present is 1950 A.D. by convention) and corresponding uncertainties were calculated from ${ }^{14} \mathrm{C}$ ages and associated analytical errors using the IntCal09 calibration curves in the Calib6 program (Reimer et al. 2009).

A more detailed, modern age model was needed to date and attribute recent event deposits in Mullet Pond to historic hurricanes that impacted the area. A Canberra GL2020RS low-energy Germanium gamma well detector measured the activity of ${ }^{210} \mathrm{~Pb}$ and ${ }^{137} \mathrm{Cs}$ at intervals ranging from $1-5 \mathrm{~cm}$ in the uppermost $40 \mathrm{~cm}$ of MLT1. Supported levels of ${ }^{210} \mathrm{~Pb}$ activity from the in situ decay of ${ }^{226} \mathrm{Ra}$ were estimated by plotting ${ }^{210} \mathrm{~Pb}$ activity with depth and identifying the nearly constant, baseline activity in the deeper samples. Supported activity was subtracted from the total activity of each sample to find the atmosphere-sourced, or unsupported, ${ }^{210} \mathrm{~Pb}$ activity. A constant flux of ${ }^{210} \mathrm{~Pb}$ from the atmosphere was assumed, and the time elapsed since each sample was at the top of the sediment column was estimated from these activity measurements (Koide et al. 1973, Robbins and Edgington 1975, Faure 1986). The initial rise and subsequent peak in ${ }^{137} \mathrm{Cs}$ activity were used to identify the sedimentary horizons associated with the advent of ( 1954 A.D.) and moratorium on ( 1963 A.D.) atmospheric nuclear weapons testing (Pennington et al. 1973).

\subsection{Sedimentary analysis}

Loss on ignition analysis was performed on the entire length of MLT1 and MLT2 at continuous, $1-\mathrm{cm}$ resolution. Samples were dried at $105^{\circ} \mathrm{C}$ for 24 hours and then combusted at 
$550^{\circ} \mathrm{C}$ for 2 hours. Before and after each process, samples were weighed to determine the relative contributions of water, organics and inorganics to the mass of the sediment (Dean 1974). The remaining inorganic ash was sieved and the sand size particles $(>63 \mu \mathrm{m})$ were retained, dried and weighed to determine the percent coarse by dry weight in each sample.

The presence of offshore foraminifera in coastal pond sediments is a valuable indicator of marine flooding; however, analyzing the microfossil assemblages along the entire lengths of MLT1 and MLT2 (> $12 \mathrm{~m}$ of sediment) would be prohibitively time consuming. We adopted a limited sampling strategy that would enable us to learn about the deposition and preservation potential of foraminifera in Mullet Pond without expending an unreasonable amount of resources. The uppermost $40 \mathrm{~cm}$ of MLT1 was sampled at 1-cm intervals to determine the modern microfossil assemblage at the site and to identify taxa possibly associated with storm deposition during historic hurricanes. The most visually obvious sand layer in each core $(\sim 292$ $\mathrm{cm}$ in MLT1 and $\sim 431 \mathrm{~cm}$ in MLT2) was also sampled for microfossil content to determine if these apparently "large" events were associated with distinctly offshore foraminifera assemblages. Coarse layers deposited in the earliest lacustrine sediments of the pond (between 500 and $540 \mathrm{~cm}$ in MLT2, Figure 2c) were also sampled to assess the long-term preservation potential of foraminifera at the site and to determine if these oldest events could still be definitively attributed to marine flooding in spite of lower sea levels and greater site-to-sea distances at the time of their deposition. To understand the evolution of the local environment from a fresh to a brackish pond, foraminifera content away from coarse layers was also assessed at approximately $1 \mathrm{~m}$ intervals in MLT1 until their first appearance in the stratigraphy was identified. Further sub-sampling refined the absence-presence (fresh-brackish) transition interval. The basal peat and sand sequences in MLT2 were also sampled for microfossil content. Beach, near-shore, and offshore surface sediment samples were also analyzed to understand the contemporary distribution of foraminiferal assemblages and constrain the likely source of microfossils deposited in Mullet Pond.

Standard methods for foraminiferal sample preparation and analysis were employed (Scott and Medioli 1980, de Rijk 1995, de Rijk and Troelstra 1997, Scott et al. 2001, Horton and Edwards 2006). Foraminifera were concentrated from $3-\mathrm{cm}^{3}$ bulk sediment samples by washing the material over $500 \mu \mathrm{m}$ and $32 \mu \mathrm{m}$ sieves and retaining the particles in this size range. When foraminiferal abundance was sufficient, up to 300 specimens were tallied from the remaining 32 $\mu \mathrm{m}$ to $500 \mu \mathrm{m}$ fraction, and benthic species were identified using criteria provided by Phleger (1965), Scott et al. (1991), Javaux and Scott (2003), and Sen Gupta (1999).

\subsection{Spectral analysis}

Thompson's Multi-Taper Method (MTM) was used to find the power spectra of the inorganic and coarse fraction time series from MLT1 and MLT2 (Huybers 2010). For MLT2, this analysis was confined to the most recent 3500 years of the time series, which was the portion of the core with the highest and steadiest sedimentation rate similar to that of MLT1

(Supplementary Figure 1). Appropriate linear fits to the calibrated radiocarbon dates were used to construct the necessary uniform time vectors, and the data were linearly detrended before the MTM was applied. The 95 percent confidence limits for the power estimations were based on a chi-squared distribution calculated from the equivalent degrees of freedom (Percival and Walden 1993). A time-bandwidth product of 3 was used, and 5 discrete prolate spheroidal sequence (dpss) tapers were applied. Peaks significant at the 95 and 99 percent confidence levels were 
identified by comparing the computed power spectra to that of a red noise process (Mann and Lees 1996; Ghil et al. 2002).

\subsection{Event detection}

In order to remove the significant, low-frequency variability identified by the spectral analysis, each coarse fraction time series was high-pass filtered so that it contained only variability on frequencies greater than $30^{-1} \mathrm{yrs}^{-1}$. This filtering isolated the coarse fraction anomalies associated with short-lived, storm deposition events from the background sediment composition variations driven by environmental changes occurring on longer timescales. A threshold value for event detection was needed to determine what magnitude of coarse fraction anomalies might be attributable to storm-induced surge events. The post-1851 A.D. portion of the record was used to calibrate the storm record by relating recent coarse fraction anomalies to the storm surge events that may have produced them. Due to a lack of a local instrumental surge record, however, it was first necessary to determine which historic hurricanes may have produced significant coastal flooding at the site.

The Sea, Lake and Overland Surges from Hurricanes (SLOSH) model was used to identify which historic hurricanes produced the largest still water level storm surges near Mullet Pond. The Atlantic Best-Track Dataset provided storm positions and maximum wind speed estimates at 6-hour intervals going back to 1851 A.D. (Jarvinen et al. 1984, Landsea et al. 2004, Landsea et al. 2008, NOAA 2010b). Rather than maximum wind speed, SLOSH uses the barometric pressure difference between the storm center and the ambient environment $(\Delta \mathrm{P})$ as the intensity parameter (Jelesnianski et al. 1992). This quantity was estimated from the BestTrack maximum wind using an empirical wind-pressure parameterization specific to the Gulf of Mexico (Landsea et al. 2004). Similarly, each storm's radius of maximum wind (RMW) was estimated using an empirical expression that relates the climatological RMW of Atlantic hurricanes to storm latitude and $\Delta \mathrm{P}$ (Vickery et al. 2000).

Bald Point is included in the model domains of three different SLOSH basins. To better assess model uncertainties, flooding events caused by Best Track storms impacting the area were modeled using three different grid domains: the Apalachicola Basin, the Cedar Key Basin, and the Gulf-Wide Extratropical Basin. The Apalachicola basin provides the highest model resolution at Bald Point but neglects the effects of remotely-produced, coastally-trapped Kelvin waves, which are sometimes generated beyond the model domain and can travel into the area of interest. Such waves can contribute significantly to the overall surge along this coastline. Hurricane Dennis in 2005 generated a coastally-trapped wave, and the operational use of the spatially-limited Apalachicola Basin to forecast the anticipated surge led to a dramatic underprediction of the coastal flooding in Apalachee Bay (Morey et al. 2006). The Cedar Key basin includes more of the coastal shelf and, thus, can better simulate trapped coastal waves when they occur; however, this basin has lower spatial resolution at Bald Point. The Gulf-Wide basin includes the whole northern Gulf of Mexico and does the best job of simulating trapped waves, but this basin also has the coarsest resolution and does not permit surges to penetrate inland.

Surges were modeled in all three basins for all Best-Track storms having maximum sustained winds of at least 100 knots (SS-Category 3) while within a $500 \mathrm{~km}$ radius of a point in the northeastern Gulf $\left(27.3^{\circ} \mathrm{N}, 85.6^{\circ} \mathrm{W}\right)$ or 34 knots (tropical storm) while within a $200 \mathrm{~km}$ radius of Mullet Pond. The uncertainty in each modeled surge was calculated from the spread among the three basins. For cases where the input parameters are perfectly known, SLOSH is 
estimated to have a 20 percent analytical error (Jelesnianski et al. 1992), which was also included in the uncertainty estimates for storm surge at Bald Point. Model topography and surge levels are both referenced to the North American Vertical Datum of 1988 (NAVD88).

Once the modern coarse fraction anomalies that corresponded in time to significant historic surges were identified, two calibration strategies using different critical values for event detection were applied. First, a low threshold (hereafter, LT) that classified most historic, positive coarse fraction anomalies as events was used. Then, a more conservative high threshold (hereafter, HT) was applied to the coarse fraction anomalies. The HT identified only values equal to or larger than the largest coarse fraction anomaly in the modern record as an event. In this way, two event chronologies, one for each detection threshold, were constructed from the coarse fraction anomaly time series.

\subsection{Constructing the event frequency time series}

A sliding 157-yr window was used to facilitate comparisons between storm frequency in the instrumental record (1851 - 2007 A.D.) and event frequency in the paleorecord. Moving averages of event frequency were obtained using the average occurrence rate of significant coarse fraction anomalies per year within the sliding 157-yr window. A time series of event frequency was produced for both the LT and HT event chronologies. Owing to the stochastic nature of hurricane landfalls, the number of storms impacting a specific site would likely vary from one sampled period to the next even if the statistics of Atlantic hurricanes were stationary through time. Thus, some portion of the variability in local flooding frequency was due to chance only, while the remainder may have resulted from actual changes in storm climate. To construct confidence intervals for the random portion of the variability, the occurrence of an event at the site was assumed to follow a Poisson process with a mean rate assigned by the historic (most recent 157-years) portion of the sediment record. Exact solutions for the $95^{\text {th }}$ and $5^{\text {th }}$ percentile confidence intervals were found (Ulm 1990), and intervals of the time series with values of event frequency outside these upper and lower bounds were identified as periods with significantly different event rates than the historic rate. Confidence intervals were calculated based on both historic HT and LT rates in MLT1, and this process was also repeated for a portion of MLT2.

Two additional time series of storm frequency were produced to assess the sensitivity of the result to the initial high-pass filtering of the data. In one case, a time series was constructed by applying the sliding window to the raw coarse fraction data without first high-pass filtering the data. In the other case, the raw data were initially filtered to find a time series of coarse fraction excursions by subtracting each coarse fraction measurement from the preceding coarse fraction measurement. The sliding window was then applied to the time series of coarse fraction excursions. In these alternate cases, the records were calibrated either by using the historic raw data or excursions to select low and high thresholds for event detection.

\section{Results}

\subsection{Description of the sediments in Mullet Pond}

Visual inspection of the cores together with a CHIRP profile revealed three main sedimentary units in Mullet Pond: basal sand, peat, and an overlying unit of dark, fine-grained 
sediment (Figure 2a). Loss on ignition and microfossil analysis located the marine transition in the stratigraphy, which divided the fine-grained sediments into a lower fresh lacustrine unit and an upper brackish lacustrine unit. Much of the detailed stratigraphy was obscured by gas in the brackish lacustrine unit; however, a prominent reflector in the upper portion of the sediments could be traced continuously across the basin (Figure $2 \mathrm{~b}$ ). This spatially-uniform reflector corresponded to a sand layer and a peak in inorganic content near $72 \mathrm{~cm}$ depth in MLT1 and 64 $\mathrm{cm}$ depth in MLT2 (Figure 2b,c). Though MLT2 was slightly longer and captured the basal sand and peat sequences, MLT1 was extracted closest to the pond's sediment depot center and captured a longer segment of the fine-grained, lacustrine sediments only (Figure 2c).

\subsection{Description of the sediment cores}

All of MLT1 and most of MLT2, with total lengths of 601 and $619 \mathrm{~cm}$ respectively, were comprised of dark, fine-grained sediment containing occasional gray clay-rich layers approximately $1-2 \mathrm{~cm}$ thick. Visually, the composition of MLT1 appeared fairly uniform throughout, whereas MLT2 contained coarse sand below $600 \mathrm{~cm}$ and peat between 550 and 600 $\mathrm{cm}$ depth. Loss on ignition analysis revealed that the bulk water content of the dark sediment was near 80 percent with the highest water content ( $~ 90$ percent) in the uppermost 15 to $20 \mathrm{~cm}$ of MLT1 (Figure 2c). The average dry weight composition of the sediment was about 70 percent inorganic with about 20 percent of this being sand and the rest finer silts and clays. Abrupt, transient peaks in coarse fraction suggested that centimeter or smaller scale sand layers were numerous in both cores. These sand fraction peaks were present in the whole of MLT1 and in the upper $530 \mathrm{~cm}$ of MLT2.

\subsection{Foraminifera content}

Foraminifera were absent from terrestrial, dune ridge, beach and near-shore samples taken at elevations above $-1 \mathrm{~m}$ MSL (Table 1). For samples taken below $-1 \mathrm{~m}$ MSL, depth (at 5 $m$ intervals) and location-specific assemblages for Ochlokonee Bay and the Gulf are summarized in Table 1. Taxa typical of subtidal marsh and brackish pond environments (Tiphotrocha comprimata, Jadammina macrescens, Ammobaculites sp., and Arenoparella mexicana) were present in the core top and in every sample taken above $\sim 330 \mathrm{~cm}$ in MLT1, which is presumably the horizon associated with sea-level intercepting the pond (Table 2). Seven intervals in the upper $40 \mathrm{~cm}$ of MLT1, all associated with coarse layers, contained marine assemblages typical of water depths of at least -1 to $-5 \mathrm{~m} \mathrm{MSL}$ (currently found 3 to $5 \mathrm{~km}$ offshore), and four of these had taxa which currently reside only at depths exceeding $-5 \mathrm{~m}$ MSL. The very prominent coarse layers near $292 \mathrm{~cm}$ in MLT1 and $431 \mathrm{~cm}$ in MLT2 contained taxa typical of offshore environments now found at depths and distances of -5 to $-10 \mathrm{~m} \mathrm{MSL}$ and 12 to $16 \mathrm{~km}$, respectively. The oldest coarse deposits in the stratigraphy $(\sim 504 \mathrm{~cm}, 510 \mathrm{~cm}$, and $531 \mathrm{~cm}$ in MLT2) contained marine assemblages typical of modern depths between -1 to $-5 \mathrm{~m}$ (Figure 2c). Foraminifera were absent from the basal peat and sand units in MLT2.

\subsection{Age control}

Eleven radiocarbon dates provided age control for MLT1 (Table 3). All but one of the calibrated ages were chronostratigraphically consistent, and the errant sample at $268-269 \mathrm{~cm}$ was 
discarded because its age was approximately 200 years younger than what would be expected based on the sequence of other calibrated ages. Based on the ten remaining dates, MLT1 had a remarkably constant sedimentation rate of $1.35 \mathrm{~mm} \mathrm{yr}^{-1}$, and a linear fit to the medians of the highest probability $1 \sigma$ calibrated ranges had an $\mathrm{R}^{2}$ of 0.998 (Figure 3a, Supplementary Figure 1). The deepest radiocarbon sample from $569 \mathrm{~cm}$ yielded an age of about $4200 \mathrm{cal}$. yrs. B.P. (Table 3 ), and linear extrapolation of the sedimentation rate to the bottom of the core suggested that the MLT1 record spans approximately the last 4500 years.

The five radiocarbon dates sampled from MLT2 were all chronostratigraphically consistent (Table 4). The linear fit to the three uppermost ages had an $\mathrm{R}^{2}$ of 0.998 and suggested a sedimentation rate of $1.2 \mathrm{~mm} \mathrm{yr}^{-1}$ above $415 \mathrm{~cm}$ depth, with much lower sedimentation rates of $0.55 \mathrm{~mm} \mathrm{yr}^{-1}$ between $542 \mathrm{~cm}$ and $415 \mathrm{~cm}$ and $0.33 \mathrm{~mm} \mathrm{yr}{ }^{-1}$ below $542 \mathrm{~cm}$ (Supplementary Figure 1). However, given the absence of a date between 415 and $542 \mathrm{~cm}$ depth and a significant change in lithology from peat to fine-grained organic sediment around $550 \mathrm{~cm}$, some uncertainty exists for the $0.55 \mathrm{~mm} \mathrm{yr}^{-1}$ rate between 415 and $542 \mathrm{~cm}$. The sedimentation rate of $1.2 \mathrm{~mm} \mathrm{yr}^{-1}$ may actually continue down to the lacustrine/peat transition. The deepest sample was taken from $616 \mathrm{~cm}$, near the bottom of the core, and returned a calibrated age of about $7950 \mathrm{cal}$. yrs. B.P.

The background, sediment-supported ${ }^{210} \mathrm{~Pb}$ activity in MLT1, measured at depths below $19 \mathrm{~cm}$, was approximately $0.035 \mathrm{~Bq} / \mathrm{g}$ (Supplementary Figure $2 \mathrm{a}$ ). Seventeen distinct ${ }^{210} \mathrm{~Pb}$ ages were calculated above this depth and ranged from 1904 A.D. to 2006 A.D (Figure 3b). The ${ }^{137}$ Cs horizons corresponding to 1954 A.D. and 1963 A.D. were identified at approximately 9.5 and 6.5 $\mathrm{cm}$ respectively (Supplementary Figure $2 \mathrm{~b}$ ). Though the long-term, radiocarbon-based sedimentation rate of $1.35 \mathrm{~mm} \mathrm{yr}^{-1}$ in MLT1 was very stable, the ${ }^{137} \mathrm{Cs}$ and ${ }^{210} \mathrm{~Pb}$ data indicated a somewhat higher sedimentation rate of $1.8 \mathrm{~mm} \mathrm{yr}^{-1}$ during the $20^{\text {th }}$ Century. The loss on ignition data showed that a significant increase in organic content accompanied the recently increased sedimentation rate. Also, sediment porosity in MLT1 peaked in the uppermost $20 \mathrm{~cm}$ with water content just under 90 percent by bulk weight. The very recent increase in sedimentation rate indicated by the modern age model of MLT1 may have been due to the uncompacted nature of the uppermost sediments or might have resulted from landscape or water quality changes caused by local human activity during the $20^{\text {th }}$ Century. To account for the recent, apparent acceleration of the sedimentation rate, a polynomial age model (Figure $3 \mathrm{~b}$ ) was fit to the ${ }^{137} \mathrm{Cs}$ horizons, ${ }^{210} \mathrm{~Pb}$ ages and uppermost, calibrated radiocarbon date of MLT1 (Table 3). This model was used to date historic sand deposits in MLT1. For MLT2, recent sand deposits were approximately dated using the uppermost linear age model based on radiocarbon dating.

\subsection{Natural history of Mullet Pond}

Based on the lowermost radiocarbon date in MLT2, the sinkhole that would eventually become Mullet Pond probably formed when a cavity in the underground limestone collapsed at least 7,000 to 8,000 yrs. B.P. The sand unit at the base of MLT2 (Figure 2a) is likely the surficial sediment that fell into the original depression during and immediately after the collapse. Based on the depth of the overlying sediments in Mullet Pond, the original depression was up to $8 \mathrm{~m}$ deep, assuming no post-collapse subsidence of the bottom. According to the radiocarbonbased age model, the $0.5 \mathrm{~m}$ of freshwater peat between 600 and $550 \mathrm{~cm}$ depth in MLT2 was deposited from about 7,000 through 5,800 cal. yrs. B.P. No foraminifera were present in the basal peat, but a peak in sand and inorganic content just above the peat interval at $531 \mathrm{~cm} \mathrm{depth}$, dated by the age model to around 5,500 yrs. B.P., was found to contain shallow marine 
foraminifera Ammobaculites dilatus and Ammobaculites exiguus (Table 1, Table 2). The presence of these taxa suggested that this earliest coarse fraction layer in Mullet Pond had a marine origin and was likely deposited during a coastal flood. A subsequent increase in baseline sand and inorganic content around the time of this coarse deposit suggested that the site was intercepted by a rising water table and transitioned into a freshwater pond.

Numerous, ephemeral peaks in coarse and inorganic fraction occasionally accompanied by marine-indicative foraminifera ( $A$. dilatus and $A$. exiguus) were detected in sediments deposited after the site became a freshwater pond (Table 1, Table 2, Figure 2c). Rising sea levels (Donnelly and Giosan, 2008) eventually intercepted the pond resulting in a transition to a brackish environment and the development of a salt marsh around the pond perimeter between 2450 and 2320 yrs. B.P. Brackish foraminifera were continuously present in all sediments sampled for microfossil content after this transition (Table 2). The fresh-to-brackish transition was also accompanied by subtle increases in baseline sand and inorganic content in both MLT1 (near $330 \mathrm{~cm}$ depth) and MLT2 (near $300 \mathrm{~cm}$ depth) (Figure 2c).

Given the spatial uniformity of the sedimentary units and deposits in Mullet Pond, MLT1 and MLT2 should both have recorded the same environmental changes and short-lived depositional events through time. However, MLT1 yielded a greater temporal resolution owing to its higher and remarkably steady sedimentation rate, thus providing the opportunity to develop an event record with uniform, sub-decadal resolution ( $\sim 7$ years with 1-cm sampling). Only the most recent $\sim 3500$ years of MLT2 had a similarly high ( $\sim 8$ years with 1-cm sampling) and uniform temporal resolution, so the storm record from MLT2 was derived from that interval only.

\subsection{Spectral properties of MLT1 and MLT2}

The power spectra of the MLT1 inorganic (Figure 4a) and coarse fraction (Figure 4b) time series both exhibited peaks significant at the 95 percent level at frequencies of $\sim 1100^{-1} \mathrm{yrs}^{-}$ ${ }^{1}, \sim 230^{-1}$ yrs. $^{-1}, \sim 70^{-1}$ yrs. $^{-1}, \sim 50^{-1}$ yrs. $^{-1}$ and $\sim 30^{-1}$ yrs. $^{-1}$. Peaks significant at the 99 percent level were present near $1100^{-1} \mathrm{yrs}^{-1}, 246^{-1} \mathrm{yrs}^{-1}, 52^{-1} \mathrm{yrs}^{-1}$, and $34^{-1} \mathrm{yrs}^{-1}$ in the power spectrum of MLT1 inorganics (Figure 4a). The coarse fraction power spectrum had peaks significant at the 99 percent level centered at $20^{-1}$ and $15^{-1} \mathrm{yrs}^{-1}$ (Figure 4b). These higher frequency peaks, close to the Nyquist frequency of $14.8^{-1} \mathrm{yrs}^{-1}$, were significant only in the coarse fraction power spectrum, which suggested that short-lived deposition events occurring on timescales near the temporal resolution of the record $(\sim 7.4 \mathrm{yrs}$.) controlled much of the variability in the coarse fraction. High-pass filtering of the coarse fraction raw data to include only variability on frequencies higher than $30 \mathrm{yrs}^{-1}$ isolated this event signal from the original time series (Figure 5a; Figure 6a,b). Based on the power spectra of the most recent 3500 years of MLT2 (Supplementary Figure 3a,b), coarse fraction anomalies for MLT2 were also found by filtering out frequencies lower than $30 \mathrm{yrs}^{-1}$ (Figure $5 \mathrm{~b}$ ). The resulting time series of MLT1 coarse fraction anomalies (Figure 6b) displayed a distribution of peaks similar to the raw coarse fraction time series (Figure 6a), but with the background variability removed.

\subsection{Historic hurricanes and calibration of the paleorecord}

SLOSH modeling of the 66 Best Track storms that met the intensity and proximity criteria revealed that fifteen hurricane-induced surges of at least $1 \mathrm{~m}$ likely occurred at Bald 
Point between 1851 and 2007 A.D. A total of eight surges exceeding $2 \mathrm{~m}$, within the provided uncertainty, were modeled in the years 1985, 1966, 1941, 1929, 1926, 1894, 1886 and 1852 (Figure 5c). The largest modeled surge was associated with Hurricane Elena in 1985, and the median modeled value of $3.2 \mathrm{~m}$ is consistent with observations of an approximately $3 \mathrm{~m}$ surge in the area during the event (Case 1986). The modeled $0.8-1.6 \mathrm{~m}$ surge from Hurricane Eloise in 1975 is also consistent with eyewitness observations of a small surge locally (Hebert 1976). However, the simulated surge from Hurricane Dennis (2005) differed significantly from observations. The surge from Hurricane Dennis was modeled to be between 0.9 and 1.6 meters at Bald Point. However, the model underestimated the actual storm tide from Hurricane Dennis, which was observed to be $2-3 \mathrm{~m}$ in western Apalachee Bay (Morey et al. 2006) (Figure 5c). The discrepancy between modeled and observed flooding magnitudes likely arose from uncertainties in the SLOSH model input. Simplifying assumptions including the use of parameterizations for the RMW, wind field, and wind-pressure relationships as well as the omission of astronomical tides, wind waves, and wave setup may account for some of the differences between the modeled still water level surges and observed storm tides. Errors in the Best Track storm intensity or position data would also add uncertainty particularly in the earlier years of the dataset. However, the intent was not to precisely hindcast historical storm tides, but rather to objectively sieve through the hundreds of Gulf storms in the Best-Track data for the few historic storms likely represented in the sediment record.

When plotted against the polynomial age model, the largest modern coarse fraction anomalies in MLT1 and MLT2 tended to coincide with significant modeled surges (Figure $5 a, b, c)$. Five of the six largest coarse fraction anomalies in MLT1 dated to surge events that were modeled or otherwise known to exceed $2 \mathrm{~m}$, within the provided uncertainty. The smallest of these is likely associated with the 1941 A.D. Hurricane, and this value was taken as the low threshold (LT) for storm detection. All coarse fraction anomalies above the LT in the modern record were coincident with modeled surges caused by historic hurricanes impacting the area. When applied to the older portions of the MLT1 record, the LT attributes all values meeting or exceeding the 1941 A.D. coarse fraction anomaly to paleohurricane events. However, not every modern surge-producing event was present in the modern sedimentary record, so the paleohurricane record likely also only documented a fraction of all storms impacting the site. The coarse fraction anomaly associated with Hurricane Elena in $1985(\sim 3.3)$ was selected as the more conservative high threshold (HT) for storm detection. The HT would qualify only the largest, modern coarse fraction anomaly, and coincidentally the largest modeled surge, as a significant event. Obviously this less sensitive detection method resulted in a greater underestimation of event occurrence; however, using the HT provided a higher degree of certainty that values exceeding the threshold correspond to significant coastal floods in the past and served as a sensitivity analyses of the result to the threshold value used.

The MLT2 time series of modern coarse fraction anomalies was very similar to MLT1 (Figure 5a,b). Hurricane Dennis was not detected in MLT2; however, and this may be due to inadequate preservation of or failure to capture the sediment-water interface. The sand deposit likely associated with Hurricane Alma was more prominent in the MLT2 sequence, and the Hurricane Elena deposit is the largest modern coarse fraction anomaly in both cores. The congruence of the upper portions of MLT1 and MLT2 suggests that the modern record is reproducible across the pond basin.

\subsection{Event frequency in the modern and paleorecord}


Since 4500 cal. yrs. B.P., 177 events exceeded the LT and 107 events exceeded the HT in MLT1 (Figure 6b,c). The resulting average event frequencies were 3.9 events/century and 2.4 events/century for the LT and HT cases, respectively. The corresponding event frequencies in the post-1851 A.D. portion of the sediment record were 3.8 events/century when the LT was applied and 0.6 events/century when the HT was applied. Thus, modern event frequency was similar to the long-term average when events were identified using the LT; however, the longterm average was four times greater than the modern event frequency when the HT was applied. According to the event frequency time series constructed with the HT, the occurrence of events at Mullet Pond must have been significantly more common during parts of the paleorecord than they were in the $19^{\text {th }}$ and $20^{\text {th }}$ centuries.

With event frequency remaining within the bounds of the 95 percent confidence interval (1.7 to 7.5 events per century) throughout the record, the LT-based time series exhibited no significant variability with respect to the historic rate of LT events (Figure 7a). Seven intervals in the HT-based time series exhibited event frequencies at or above the upper bound of the confidence interval (about 3.0 events per century): an approximately 300-year interval centered at 3800 cal. yrs. B.P. and a 100-year interval centered near 3550 cal. yrs. B.P. each with about 3.8 events per century, a 100-year interval centered near 3300 cal. yrs. B.P. with about 4.5 events per century, an approximately 500-year period spanning 2800 to 2300 cal. yrs. B.P. with a peak of 5.5 events per century near 2500 cal. yrs. B.P., a 50 to 100 -year interval around 1200 cal. yrs. B.P. with 3.8 events per century, an approximately 50-year interval around 900 cal. yrs. B.P. with about 3.2 events per century, and an approximately 100-year interval with about 4.5 events per century around $700 \mathrm{cal}$. yrs. B.P. Four intervals in the HT-based record had event frequencies below the lower, $5^{\text {th }}$ percentile bound of the confidence interval for the historic rate. These decadal-to-centennial scale intervals, each averaging no more than one HT event every 200 years, were centered near 1800, 1650 350, and 100 cal. yrs. B.P. (Figure 7b). A cumulative plot of HT events with time showed pronounced variability in its slope (event frequency), while the cumulative plot of the LT events was more linear and suggested modest changes in event frequency through time (Figure 6c).

Though age models and temporal resolutions differ between the two cores, the time series of hurricane frequency constructed using the last 3500 years of MLT2 reveals many of the same features present in the MLT1 time series (Supplementary Figure 4a,b). The biggest differences are present between 3000 and 3500 yrs. B.P., when the MLT2-based time series suggests hurricane frequency was most elevated. Also, the overall frequency of storms in the MLT2 record is lower, and this can likely be attributed to the core's lower temporal resolution, which would increase the classification of multiple, sequential events as single events. These similar time series were achieved by applying identical procedures to materials taken from two separate coring locations, and these results suggest that the storm record is reasonably reproducible across the Mullet Pond basin.

\section{Discussion}

\subsection{Coarse fraction anomalies as hurricane deposits}

As the power spectrum of the coarse fraction time series suggests, the most significant variability in sand content occurred on relatively short timescales near the sampling resolution $(\sim$ 
7 yrs.). Transient increases in the abundance of larger ( $>63 \mathrm{um}$ ) particles in the pond sediments could be caused by short-lived transitions to a higher-energy environment, which would occur during flooding events. The sandy soils, low relief of the carbonate platform, and absence of stream and river networks on the local landscape suggest that terrestrial runoff during rain events is minimal (Puri and Vernon 1964); moreover, Mullet Pond has shallow banks and a small watershed (Figure 1c). Furthermore, the water level of the pond is essentially the same as the groundwater level, so freshwater flooding would simply cause the pond to "fill up" thereby limiting the lateral transport of terrestrial sediment into the basin. If terrestrial, freshwater flooding events have played a role in depositing sand into Mullet Pond, then this process would likely be most prominent when the collapse feature was young and the relief surrounding its sediment depot center was greatest. The absence of coarse grain deposits in the 1200-year basal peat sequence in MLT2 strongly suggests that terrestrial runoff did not play a role in transporting sand into the pond at the time when the basin would have been configured to be most susceptible to this process. It is therefore unlikely that freshwater flooding would have played a role in any subsequent coarse layer deposition.

The oldest sand deposit overlying the peat in MLT2, dated to around 5500 yrs. B.P., contained marine foraminifera (Table 2, Figure 2c). Given subsequent rising sea levels and decreasing site-to-sea distances, this oldest deposit serves as a precedent and indicates that Mullet Pond would have been susceptible to inundation from marine flooding events since that time. While the presence of offshore taxa has been considered a sufficient basis for identifying paleohurricane deposits (Hippensteel and Martin 1999, Collins et al. 1999, Hippensteel and Martin 2000, Hippensteel et al. 2005, Hippensteel 2008, Scott et al. 2003), the absence of foraminifera in other sand layers does not rule out a marine origin for deposits (Williams 2010). Dune, beach and nearshore surface samples above $-1 \mathrm{~m}$ elevation (MSL) were absent of foraminifera, which suggests that coarse deposits containing offshore taxa were likely produced only by relatively more dynamic coastal flooding events (Table 1).

The CHIRP profile of Mullet Pond (Figure 2b), though mostly obscured by gas, suggested that the upper sediment stratigraphy is spatially uniform across the basin. The reproducibility of both modern and paleohurricane records from the MLT1 and MLT2 cores supports this (Figure 5a,b, Supplementary Figure 4). Horizontal continuity of the coarse deposits would indicate they originated when sand suspended by surge and wave action was advected over the dune ridge or through the marsh and then subsequently settled out after the flooding had subsided. Moreover, the general features of the MLT1 record of storm frequency were robust regardless of whether and how the raw coarse fraction data were filtered (Supplementary Figure 5), which suggests that the vast majority of coarse fraction anomalies are not merely artifacts of how the raw data were treated.

Given the relative seismic stability of the region, tsunamis in the Gulf of Mexico seem to be an unlikely cause of the coastal floods. Storm-induced coastal flooding remains the most likely mechanism for the production of the thin, coarse-grained deposits in Mullet Pond. While coastal flooding can occur during non-tropical storms, every significant coarse fraction anomaly in the modern portion of the record was contemporaneous with a historic hurricane either documented or deemed capable via modeling of generating coastal flooding at the site. We therefore conclude that coarse fraction anomalies in the Mullet Pond record provide a reasonable proxy for local tropical cyclone-induced storm surges.

\subsection{Surges and sedimentary signatures of historic hurricanes}


The post-1851 A.D. period covered by the Best Track Dataset was represented by the upper 20 or $25 \mathrm{~cm}$ of MLT1, depending on whether the linear or polynomial age model was applied. The polynomial age model, which took into account the recent increase in the sedimentation rate, suggested that nearly every significant coarse fraction anomaly coincided with a significant (at least 2 meters), historic surge. Not every historic hurricane with a modeled surge exceeding 2 meters was detected in the recent sediment record, but the actual storm tides may have been smaller than the modeled surges in some cases. Moreover, the age model for the last half of the $19^{\text {th }}$ Century was based on an interpolation between the upper ${ }^{137} \mathrm{Cs}$ and ${ }^{210} \mathrm{~Pb}$ constraints and a radiocarbon date at $80 \mathrm{~cm}(\sim 545 \mathrm{cal}$. yrs. B.P.). The more tenuous age controls for the $19^{\text {th }}$ Century chronology may have prevented the proper attribution of significant coarse fraction anomalies to large, modeled surge events such as the one associated with the 1852 A.D. Hurricane (Figure 5c). While the sediment record may not document every hurricane that affected the area since 1851 A.D., the correspondence of the largest, recent coarse fraction anomalies with the most significant documented hurricane events in the area is encouraging.

Although the largest historic hurricane events were represented in the record, some smaller events likely went undetected resulting in an underestimate of the number of storms impacting the site through time. While 66 historic storms met the intensity and proximity criteria for SLOSH modeling and 15 of these were modeled to have surges of at least $1 \mathrm{~m}$ at the site, only six modern storm deposits were detected in the modern portion of the sediment record. This translates into a detection rate of approximately 9 percent of all modeled storms and 40 percent of storms with $1+\mathrm{m}$ of modeled surge, respectively. Undercounting may also have occurred as a result of limited sampling resolution. For example, the hurricanes of 1894 and 1896 A.D. occurred in such quick succession that they could not be distinguished as two separate events in MLT1 or MLT2 given the temporal resolution of the sediment records (Figure 5). Multiple storms occurred in the years 1985 and 1886 A.D., and these storms would also be lumped together as single events. Undercounting of paleohurricanes likely occurred throughout the record, and more storms were probably missed during periods of greater storm frequency (Woodruff et al. 2008a). Therefore the actual amplitude and statistical significance of the storm frequency variations through time were likely greater than what was derived from the sediment record.

Shallow, benthic (-1 to $-5 \mathrm{~m} \mathrm{MSL}, 3$ to $5 \mathrm{~km}$ ) foraminifera were present in deposits associated with the 1941 A.D. Hurricane and possibly Dennis in 2005 A.D. (Table 2, Figure 5a). Benthic taxa that currently reside in marine sediments between -5 and $-10 \mathrm{~m} \mathrm{MSL}$ depth (5 to 16 $\mathrm{km}$ offshore) were identified in the storm deposits of Elena (1985 A.D.), 1926/29 A.D., and 1894/96 A.D. The shallow marine assemblage was also present in an interval spanning 1797 1823 A.D., while the deeper and more offshore species were found at $\sim 1780$ A.D. (Table 2, Figure 2c). While we have not identified written records of historic hurricane strikes near Apalachee Bay between 1797 and 1823 A.D. (Ludlum 1963), it is possible that storms impacting this sparsely populated region in the late $18^{\text {th }}$ and early $19^{\text {th }}$ centuries may have gone undocumented. The foraminifera-rich deposit dating to $\sim 1780$ A.D. is associated with the largest coarse fraction anomaly of the last 500 years in MLT1 (Figure 6b). This deposit dates to Solano's Hurricane of 1780 A.D.- one of three devastating hurricanes that occurred during the deadliest Atlantic hurricane season on record. This well documented storm killed thousands at sea in the eastern Gulf of Mexico when it intercepted a fleet of Spanish ships en route to capture the Florida Panhandle from the British (Ludlum 1963). Solano's Hurricane appears to also be 
documented in an independent, tree ring isotope-based paleohurricane record from southern Georgia (Miller et al. 2006). As previously noted, the presence of distinctly offshore taxa in a coastal pond serves as a compelling indicator of marine inundation, but foraminifera may not always be present in storm deposits.

\subsection{Site sensitivity to storm surge through time}

Much of the criticism against using the historic Atlantic hurricane record to detect secular trends in tropical cyclone activity is related to the improvement of storm detection and observation through time (Landsea 2007, Chen et al. 2009). A similar criticism could be leveled against the paleohurricane record contained in Mullet Pond, which should have experienced increasing susceptibility to storm surges as sea level rose and, therefore, should have become a more complete record of storm activity toward present. Debate exists over the evolution of sea level in the Gulf of Mexico during the Holocene. Some investigators have proposed that Gulf sea level has risen in a generally smooth and continuous fashion through the mid-late Holocene (Otvos 2001, Törnqvist et al. 2004, Wright et al. 2005, Donnelly and Giosan 2008, Milliken et al. 2008, Simms et al. 2009), while more complex sea level curves for the region have also been suggested (Stapor et al. 1991, Tanner 1992, Morton et al. 2000). Dating of relic beach ridges along the northern Gulf of Mexico has been offered as evidence for periods of higher than modern sea level $(\sim+2 \mathrm{~m})$ during the mid-Holocene (Morton et al. 2000, Blum et al. 2003). However, if sea level had been significantly higher than modern at any time in the last 7,000 years, then a near-shore or open marine sequence should be evident from the lithology and microfossil profile of MLT2, which spans the last 8000 years. No such evidence for a significant late Holocene sea level highstand exists in the sedimentary archive of Mullet Pond (Figure 2c, Table 2).

The combined effects of continuous sea level rise and shoreline retreat should have colluded to increase the frequency of hurricane inundations through time. However, the record does not provide evidence for such a trend and possesses variability that cannot be explained by steady sea level rise. In fact, sea level along the Gulf Coast of Florida has been placed at 1.2 to $1.5 \mathrm{~m}$ below modern levels around 2500 yrs. B.P. (Wright et al. 2005), when storm frequency peaked in the Mullet Pond record. Moreover, the decline in storm events since 600 cal. yrs. B.P. is inconsistent with subsequently rising sea levels and associated increasing susceptibility to inundation. With the 100-year coastal still water flood level near Bald Point purported to be 4.5 $\mathrm{m}$ (Ho and Tracey 1975), the surge potential in Apalachee Bay is larger than the proposed $\sim 3 \mathrm{~m}$ sea level rise that occurred during the entire period spanned by the MLT1 record (Wright et al. 2005, Donnelly and Giosan 2008). Today, a $4.5 \mathrm{~m}$ surge would submerge most of Bald Point, including the eastern half of the peninsula where Mullet Pond is located. Given the modern bathymetry of Apalachee Bay, the maximum site-to-sea distance 4500 years ago would have been about $3.8 \mathrm{~km}$. A recent examination of the surge deposit from Hurricane Ike in Texas found that suspended littoral and offshore sediments containing foraminifera were transported almost $3 \mathrm{~km}$ inland and were then preserved in subaerial environments (Williams 2010). These findings suggest that appropriate depositional settings can preserve microfossil-based paleohurricane records stretching back thousands of years. Foram dissolution and bioturbation complicate microfossil-based paleohurricane reconstructions in many settings (Hippensteel and Martin 1999, Collins et al. 1999, Hippensteel and Martin 2000, Hippensteel et al. 2005, Hippensteel 2008, Scott et al. 2003); however, lateral continuity of distinct storm layers and 
prolonged microfossil preservation indicate that these processes play a limited role in Mullet Pond. The presence of calcareous marine foraminifera in a sand layer dating to $5500 \mathrm{cal}$. yrs. B.P. suggests that the site has been recording surge events for almost six millennia (Table 2, Figure 2c). At modern coastal sites along Apalachee Bay, where the topography is very lowlying and the surge potential is extreme, it is likely that overwash frequency is dominated by the frequency and magnitude of marine flooding events rather than changes in geographic boundary conditions through time. We deduce that the changes in flooding frequency suggested by the sedimentary record in Mullet Pond primarily reflect variability in storm climate rather than changes in site sensitivity.

\subsection{Comparisons with other paleohurricane records}

Given the stochastic nature of hurricane landfalls, changes in the frequency of storms at one particular site may not necessarily reflect larger-scale changes in storm frequency. The discrepancy between site-specific and basin-wide activity may be largest when short time periods are considered. For this reason, any very recent trend in Atlantic-wide hurricane frequency caused by anthropogenic climate change would be nearly impossible to detect in a single sedimentary record. When longer time periods are considered, changes in local hurricane frequency are more likely to reflect larger-scale changes in storm climate (Woodruff et al. 2008a). Other sediment-based paleohurricane records from the Caribbean, Northeastern U.S., and the northern Gulf of Mexico have documented significant multi-centennial to millennialscale variability in hurricane frequency similar to the centennial to multi-centennial variability identified in the Mullet Pond reconstruction, though the timing and extent of the variability differs somewhat among the records (Liu and Fearn 1993, Liu and Fearn 2000, Scileppi and Donnelly 2007, Donnelly and Woodruff 2007).

Liu and Fearn $(1993,2000)$ identified low-frequency variability in the number of visible sand layers deposited by hurricanes impacting Western Lake, Florida. They suggested that longterm shifts in atmospheric circulation directed the majority of hurricanes toward either the Gulf or U.S. East Coast resulting in alternating hyperactive (from 3400 to 1000 cal. yrs. B.P.) and quiescent storm phases (between 5000 to 3400 cal. yrs. B.P. and after 1000 cal. yrs. B.P.) in the Gulf of Mexico. This Bermuda High Hypothesis has found support from studies of the instrumental record that have identified high-frequency variability in the dominant tracks of modern Atlantic hurricanes (Elsner et al. 2000, Elsner 2003, Holland 2007, Kossin and Camargo, 2009). However, a paleohurricane record based on salt marsh cores from Alder Island, NY exhibited a period and phase of variability similar to that of the Gulf Coast record (Scileppi and Donnelly 2007). Hurricane inundation layers were most abundant in the Alder Island marsh between 3200 and 700 cal. yrs. B.P. but were rare between 700 and 300 cal. yrs. B.P. Another record documenting intense hurricane strikes in the Caribbean indicated a similar pattern of activity over the last 5000 years in Vieques, Puerto Rico (Donnelly and Woodruff 2007). The stormiest intervals at Vieques were from 5500 to 3700 cal. yrs. B.P., 2500 to 1000 cal. yrs. B.P. and after 250 cal. yrs. B.P., while the calmest periods occurred from 3700 to 2500 cal. yrs. B.P. and 1000 to $500 \mathrm{cal}$. yrs. B.P. The authors argued that the local frequency of storms at Vieques was influenced by the low-frequency behaviors of the ENSO and the West African Monsoon-a hypothesis inspired by the instrumental record (Goldenberg and Shapiro 1996) and supported by paleorecords of these climatic phenomena (Moy et al. 2002, Nguetsop et al. 2004). In contrast to storm track-driven changes, this variability could drive large-scale, basin-wide variations in 
storm frequency and possibly intensity. One recent paleohurricane record developed from the sediments of Laguna Madre in South Texas produced no evidence for significant variability in intense, landfalling hurricane frequency during the last five millennia (Wallace and Anderson 2010). However, similar to the previously discussed paleohurricane records from the Caribbean and Gulf, overall storm detection rates at the site are lower than one event every two hundred years. Such low annual probabilities of occurrence make it difficult to objectively identify or detect meaningful changes in local storm climate through time. Another recent study based on marsh sediments from Mattapoisett, Massachusetts also did not detect large variations in storm frequency over the last two millennia (Boldt et al. 2010). However, with a probability of occurrence exceeding one storm per century, the marsh had a high sensitivity to overwash relative to many other paleohurricane sites, which suggested that significant variability in the late Holocene tropical cyclone frequency may have been confined to intense hurricanes only. The significant variability in the frequency of HT events compared with the relative constant frequency of LT events in Mullet Pond is consistent with this hypothesis.

The Mullet Pond reconstruction shares many features with a 1500-year reconstruction of basin-wide landfalling Atlantic hurricanes, which was based on a compilation of several paleohurricane records including most of those already discussed (Mann et al. 2009) (Figure $8 \mathrm{a}, \mathrm{b})$. Both the paleorecord compilation and the Mullet Pond record show increasing storm frequency between 1500 and $1000 \mathrm{cal}$. yrs. B.P. and a prolonged decline in hurricane landfalls beginning after 600 cal. yrs. B.P. The spike in hurricane landfalls that occurs just prior to 600 cal. yrs. B.P. in the Mann et al. (2009) reconstruction is present in the Mullet Pond record but was dated approximately 100 years earlier. This discrepancy may be authentic or merely result from the differences between the Mullet Pond age model and the merged age models and associated uncertainties of the other paleohurricane reconstructions.

While the available Atlantic paleohurricane reconstructions share some similar characteristics, significant differences also exist. Many factors contribute to these differences. The local sedimentary expression of a basin-wide change in overall Atlantic hurricane frequency and/or intensity could be quite different depending on a host of site-specific and regional factors. Discrepancies in hurricane reconstructions may reflect differences in local storm frequency and intensity distributions, age models, temporal resolutions of the records, flooding thresholds, local sea level rise and associated geomorphological changes. Owing to more frequent inundations and more complete detection of events, the record we present here provides a more detailed history of Holocene hurricane climate than have other records. Mean storm frequencies over the last 2500 years were 0.32 storms/century at Western Lake, 0.52 storms/century at Alder Island, 0.68 storms/century at Vieques, 1.2 storms/century at Mattapoisett, and between 1.8 and 4 storms/century at Mullet Pond depending on whether the HT or LT time series was considered (Figure 9). This wide range of local landfall rates likely results both from geographic differences in the number and intensity distribution of hurricanes affecting each region and from the local susceptibility of each site to inundation by storm surge. Region-specific variability in hurricane frequency and intensity through time may have also contributed to differences among late Holocene paleohurricane records.

The Western Lake, Vieques and Alder Island records were developed from sites that are relatively difficult to inundate; therefore, these records likely documented only the largest hurricane-induced surges (Liu and Fearn 2000, Scileppi and Donnelly 2007, Woodruff et al. 2008a, Woodruff et al. 2008b). As suggested by their much higher paleohurricane frequencies, Mullet Pond and Mattapoisett Marsh are more susceptible to smaller storm surges and can be 
inundated by a broader range of surge events. Changes in the intensity distribution of hurricanes occurring in concert with changes in storm frequency could cause the frequency of storm deposits in sites with different flooding susceptibilities to diverge. Numerical modeling of late $21^{\text {st }}$ century hurricane climatology has suggested that declines in overall Atlantic hurricane frequency could occur simultaneously with a broadening of the intensity distribution of hurricanes leading to fewer but more intense storms (Emanuel et al. 2008, Gualdi et al. 2008, Knutson et al. 2008, Zhao et al. 2009, Bender et al. 2010). However, recent warming and increased hurricane frequency in the Atlantic has purportedly been accompanied by a disproportionate increase in the occurrence of intense hurricanes (Emanuel 2005, Webster et al. 2005, Hoyos et al. 2006, Elsner et al. 2008, Jagger and Elsner 2008). When considering the climate system feedbacks likely associated with the atmospheric and upper ocean anomalies generated by tropical cyclones (Hart et al. 2007, Hart 2010), it seems likely that significant changes in the frequency of storms would also change their intensity statistics.

Although the magnitude of the coarse fraction anomaly associated with a hurricane is not necessarily an indication of storm intensity, some of the coarsest deposits do contain evidence of extremely energetic events. A few of the most prominent coarse deposits were sampled for microfossils and found to contain marine taxa common to deeper, offshore environments. These taxa, not typical of a coastal pond or salt marsh, included Brizalina spathulata, Ammonia beccarii and radiolarians. For example, deposits dating to 2100 and 3670 cal. yrs. B.P., when sea level was at least a meter lower than modern (Wright et al. 2005), contained taxa found at modern water depths of at least $-5 \mathrm{~m}$ in the region (Table 1, Table 2). Given the shallow bathymetry of Apalachee Bay, the foraminifera were transported at least $12 \mathrm{~km}$ before being deposited into Mullet Pond (Table 1). The presence of these taxa suggests large deposits like these were produced by violent events capable of transporting offshore sediment a considerable distance.

Understanding the relationship between storm frequency and intensity distribution during the last few thousand years will require a multi-site approach. A suite of records from closely-spaced sites with different flooding thresholds but the same history of storm strikes is needed to quantify the relative contributions of storm frequency and intensity to variability in hurricane activity. More thorough and detailed microfossil analysis, though very time consuming, could also aid in constraining flooding event intensity for the most intense paleohurricane events by identifying the provenance of the marine sediment in the resulting overwash deposit.

\section{Conclusions}

The Mullet Pond record indicates that the most active interval for tropical cyclones in the Northeastern Gulf of Mexico during the late Holocene was 2800 to 2300 cal. yrs. B.P. Large storm deposits were rarely detected between 1900 and 1600 cal. yrs. B.P. and after 400 cal. yrs. B.P. A decline in the number of large storm deposits, which began around 600 years ago, has persisted through present with below average frequency over the last 150 years when compared to the preceding five millennia. However, given the stochastic nature of hurricane landfalls, any trend in basin-wide hurricane frequency during the late $20^{\text {th }}$ century would not be detectable in a single sedimentary record. With an approximately 7 year temporal resolution and a record mean storm frequency of 3.9 events per century, Mullet Pond provides a richer and more detailed archive of storm activity than other existing paleohurricane records. The record presented here 
provides further evidence for significant variability in the frequency of high magnitude storm events in the Gulf of Mexico during the late Holocene. When all events were considered, however, variations in local storm frequency could be explained entirely by the random clustering of events in time. This finding suggests that variability in flooding frequency at this and other Atlantic and Gulf paleohurricane study sites might have been controlled by changes in the intensity distribution of hurricanes rather than changes in overall storm frequency.

The successful development of a high-resolution paleohurricane record from Mullet Pond indicates that coastal sinkholes can serve as valuable archives of past hurricane activity. These depositional basins can have high sedimentation rates that make sub-decadal resolution records possible. As valuable indicators of marine provenance, foraminifera have served as definitive indicators of coastal flooding in back-barrier depositional settings. Good foraminifera preservation together with low bioturbation make Mullet Pond and similar sinkhole environments good targets for future microfossil-based paleohurricane research. The presence of calcareous, marine microfossils as early as 5500 cal. yrs. B.P. serves as evidence that the site has been periodically inundated for over five millennia and proves that prolonged preservation of foraminifera is possible in these environments. On carbonate platforms where sinkholes are often abundant, topography is low and surge penetration is extensive, a very large number of long, high-resolution paleohurricane records likely exist and await discovery. Ongoing efforts to identify and develop paleohurricane records from the geologic register will further clarify how tropical cyclones have interacted with late Holocene climate variability and change.

\section{Acknowledgments}

Funding for this research was supported by the National Science Foundation and the Coastal Ocean Institute. P. Donnelly provided assistance with fieldwork and M. Gomes, S. Moret and S. Zipper assisted with laboratory analysis. Source code for the SLOSH model was provided by the National Hurricane Center (NOAA), and J. Dusenberry assisted with setting up the model. The Florida State University Marine Laboratory provided lodging during fieldwork. This research was completed during an American Meteorological Society Graduate Fellowship, National Science Foundation Graduate Fellowship and Coastal Ocean Institute Fellowship. This work was further supported by National Science Foundation award \#OCE-0903020. This is a contribution of IGCP 495 - 'Holocene land-ocean interactions: driving mechanisms and coastal responses'. 

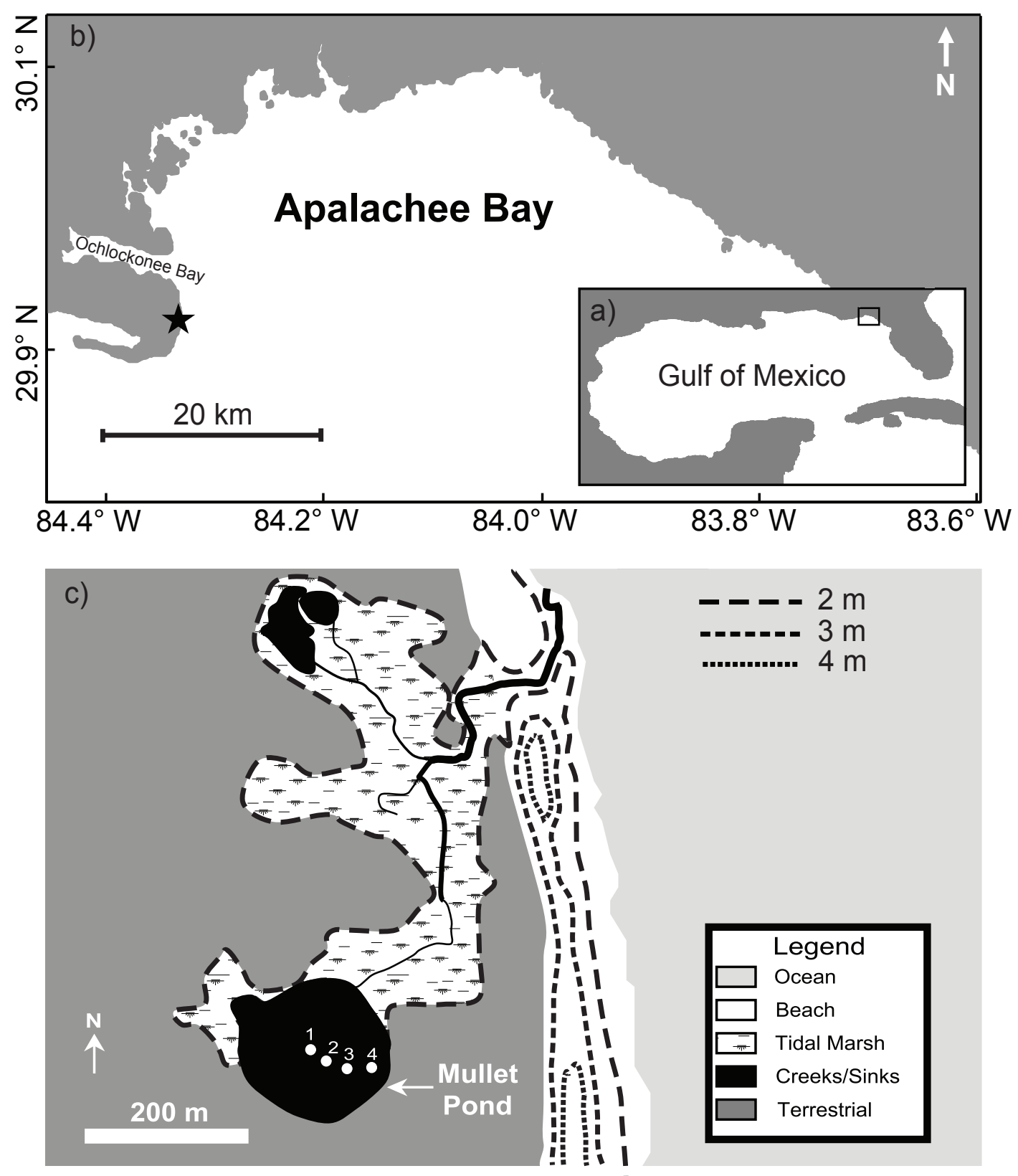

Figure I - Regional and local site maps. Panel (a) shows the Gulf of Mexico with the location of Apalachee Bay indicated by the black rectangle. Panel (b) is a regional map of Apalachee Bay showing the Bald Point peninsula near $29.9^{\circ} \mathrm{N}$ and $84.4^{\circ} \mathrm{W}$, and the location of Mullet Pond is indicated by the black star. Panel (c) is a local site map showing that Mullet Pond is situated approximately $350 \mathrm{~m}$ to the west of the Bay at the southernmost extent of a salt marsh.

Numbered core locations are shown as white circles. Mullet Pond is connected to the Bay by the tidal creek to the north but is otherwise separated from the ocean by a $3-4 \mathrm{~m}$ beach dune ridge $200 \mathrm{~m}$ to the east. Topography between 2 and $4 \mathrm{~m}$ (NAVD88) is contoured at I m intervals. The marsh surface and seaward portions of the beach have elevations of less than $2 \mathrm{~m}$. The highest elevations ( 3 to $4 \mathrm{~m}$ ) exist along the dune ridge axis on the western portion of the beach, though the ridge is slightly lower in front of the pond and along southern portion of the marsh. Most of the landscape is nearly flat with an elevation between 2 and $3 \mathrm{~m}$. 

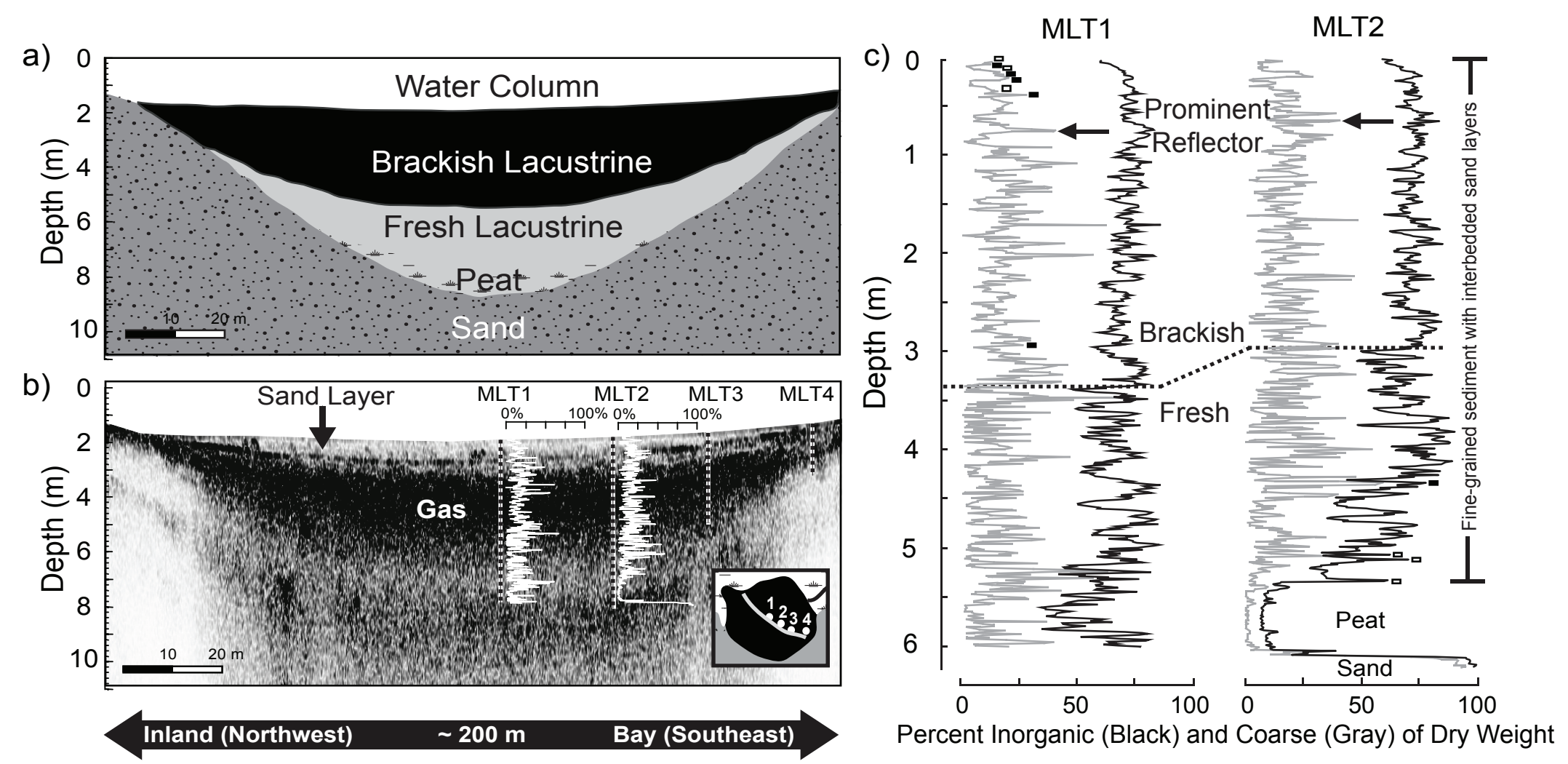

Figure 2 - Mullet Pond stratigraphy. Panel (a) is a cross-sectional drawing of the major stratigraphic units of the sediments in Mullet Pond: basal sand overlain by peat, then fresh lacustrine mud, followed by brackish mud. Panel (b) is a CHIRP profile of the sediments taken from the northwest (left) to the southeast (right) and approximately transecting all four coring locations. The inset in the lower right corner of panel (b) is a planar map of Mullet Pond showing the coring locations and the path of the transect. The dark, laminar reflector that stretches continuously across the basin near the sediment surface corresponds to a sand layer and a peak in inorganic content near $72 \mathrm{~cm}$ depth in MLTI and $64 \mathrm{~cm}$ depth in MLT2. Much of the signal was attenuated by gas in the brackish lacustrine portion of the sediments, and the resulting image of the underlying sediments was obscured. Coring locations are shown as dashed lines, and the coarse fraction by dry weight data for MLTI and MLT2 are shown to the right of the coring locations. Panel (c) shows both the percent inorganic (black) and percent coarse (gray) content by depth in MLTI and MLT2 in greater detail. Sand, peat and fine-grained (fresh and brackish) units are denoted. The corresponding depths of the prominent reflector in the CHIRP profile are marked by black arrows in both the MLTI and MLT2 loss on ignition data. The approximate location of the fresh-to-brackish transition in both cores ( $330 \mathrm{~cm}$ in MLTI and $\sim 300 \mathrm{~cm}$ in MLT2) is indicated by a black dashed line. Intervals containing shallow (-I to $-5 \mathrm{~m} \mathrm{MSL}$ ) marine foraminifera are indicated by open rectangles, and intervals where offshore (-5 to $-10 \mathrm{~m} \mathrm{MSL}$ ) taxa were detected are indicated by closed (black) rectangles (see Tables I and 2). 


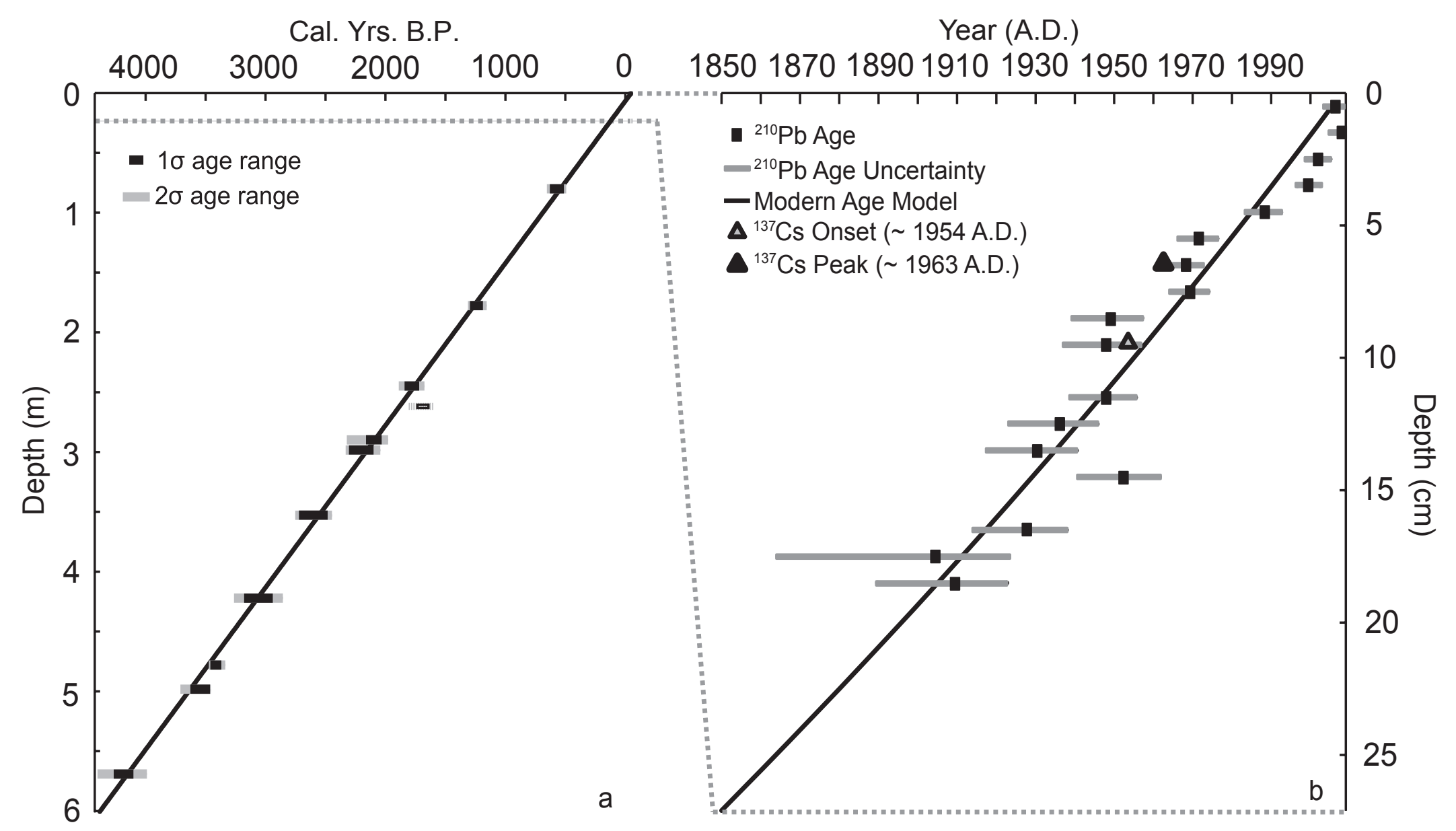

Figure 3 - MLTI age model. Panel (a) shows eleven radiocarbon-based calendar age ranges for terrestrial plant fragments taken from MLTI versus the depths from which they were collected in the core. Calendar ages and ranges in years before 1950 A.D. were found from I4C ages and uncertainties using the IntCal09 calibration dataset in the Calib6 program (Reimer et al. 2009). See Table 3 for details. One-sigma (black) and two-sigma (gray) age ranges are shown for each date, and a linear fit (black line) to the median of the highest probability one-sigma age ranges reveals a roughly constant sedimentation rate of $1.35 \mathrm{~mm}$ yr-I throughout the $60 \mathrm{I} \mathrm{cm} \mathrm{(or} \sim 4450$-year) record. One-sigma and two-sigma age ranges for the anomalous date at $268-269 \mathrm{~cm}$, which was not included in the development of the linear age model, are shown as a black open rectangle and a gray dashed line, respectively. Panel (b) shows an alternate age model with A.D. dates for the uppermost $27 \mathrm{~cm}$ of MLTI. This age model is based on $210 \mathrm{~Pb}$ ages, I37Cs horizons and the uppermost radiocarbon date at $80 \mathrm{~cm}$ depth. The seventeen $210 \mathrm{~Pb}$ ages and associated uncertainties are shown as black squares and gray bars respectively. The 137Cs horizons associated with the advent of ( 1954 A.D.) and moratorium on ( 1963 A.D.) atmospheric nuclear weapons testing are shown as an open and a closed (black) triangle respectively. A second-order, polynomial fit (black curve) to these data is shown, and this age model accounts for the apparent increase in sedimentation rate during the 20th Century. 


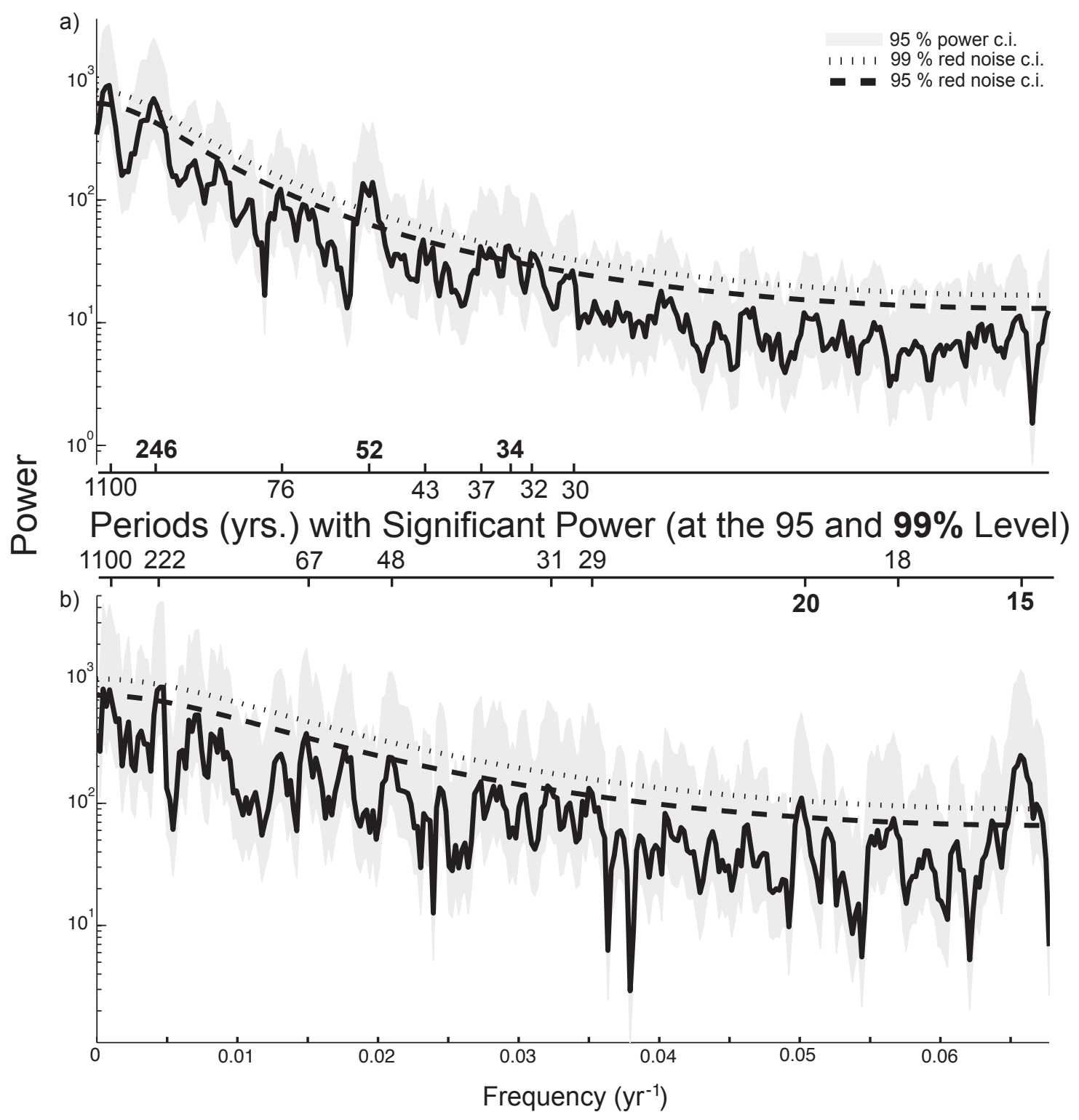

Figure 4 - Power spectra of MLTI inorganics and coarse fraction time series. Panel (a) shows the power spectrum of the MLTI time series of percent inorganics. The solid, black curve is the power calculated for each frequency bin and the gray shading is the 95 percent confidence interval of that power calculation. The dashed and dotted curves are the 95 and 99 percent confidence intervals for a comparable red noise power spectrum. Periods (in years) corresponding to frequencies with calculated power exceeding the 95 and 99 percent red noise confidence intervals are labeled in regular and bold fonts respectively. Panel (b) shows the same analysis for the MLTI time series of percent coarse $(>63 \mu \mathrm{m})$. 


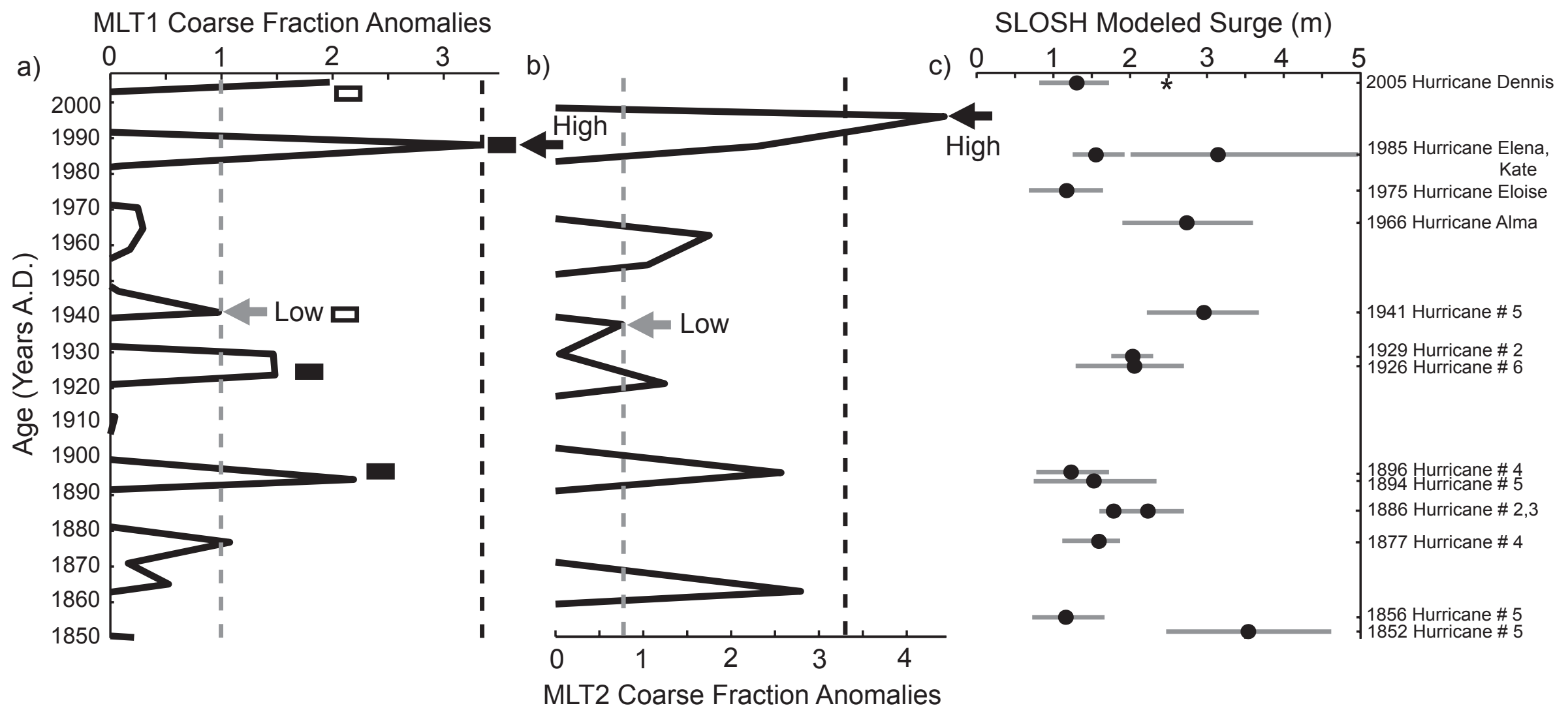

Figure 5 - Modern event deposits and historic surge events. Panel (a) and (b) show the positive coarse fraction anomalies resulting from the removal of the low-frequency background from the raw MLTI and MLT2 data, respectively. These coarse fraction anomalies represent the high-frequency ( $<30$ years) variability in the modern coarse fraction time series. In both MLTI and MLT2, the coarse fraction anomalies that form the basis for the low (LT, gray dashed line) and high thresholds (HT, black dashed line) used for storm detection were related to hurricanes in I94I A.D. (gray arrow) and I985 A.D. (Hurricane Elena, black arrow), respectively. Intervals where shallow marine (-I to $-5 \mathrm{~m}$ MSL) and offshore ( -5 to $-10 \mathrm{~m} \mathrm{MSL}$ ) foraminifera were detected in MLTI are indicated by open and closed rectangles, respectively (see Tables I and 2). The magnitude of historic (I85I - 2008 A.D.) storm surges at Mullet Pond, which were estimated using the Best Track dataset and the SLOSH model, are shown in panel (c). The estimated maximum surge heights (in meters above NAVD88) for the fifteen events with modeled surges of at least I $\mathrm{m}$ are shown (black dots) along with the uncertainty (gray bars) in each surge estimate. The shown uncertainty in the surge estimates resulted from the combination of domain-specific factors and the analytical error of the SLOSH model. The A.D. year of occurrence of each significant $(>1 \mathrm{~m})$ surge is labeled to the far right along with either the name of the storm or its number of occurrence within that year. For example, 194I A.D. Hurricane \# 5 was the fifth North Atlantic storm to achieve tropical storm strength in that year. Multiple significant surges occurred in the years 1886 and 1985 A.D. Hurricane \# 3 produced the larger of the two surges in I886 A.D. and Hurricane Elena produced the larger of the two surges occurring in 1985 A.D. The observed surge from Hurricane Dennis near Bald Point is indicated by the asterisk (Morey et al. 2006). 

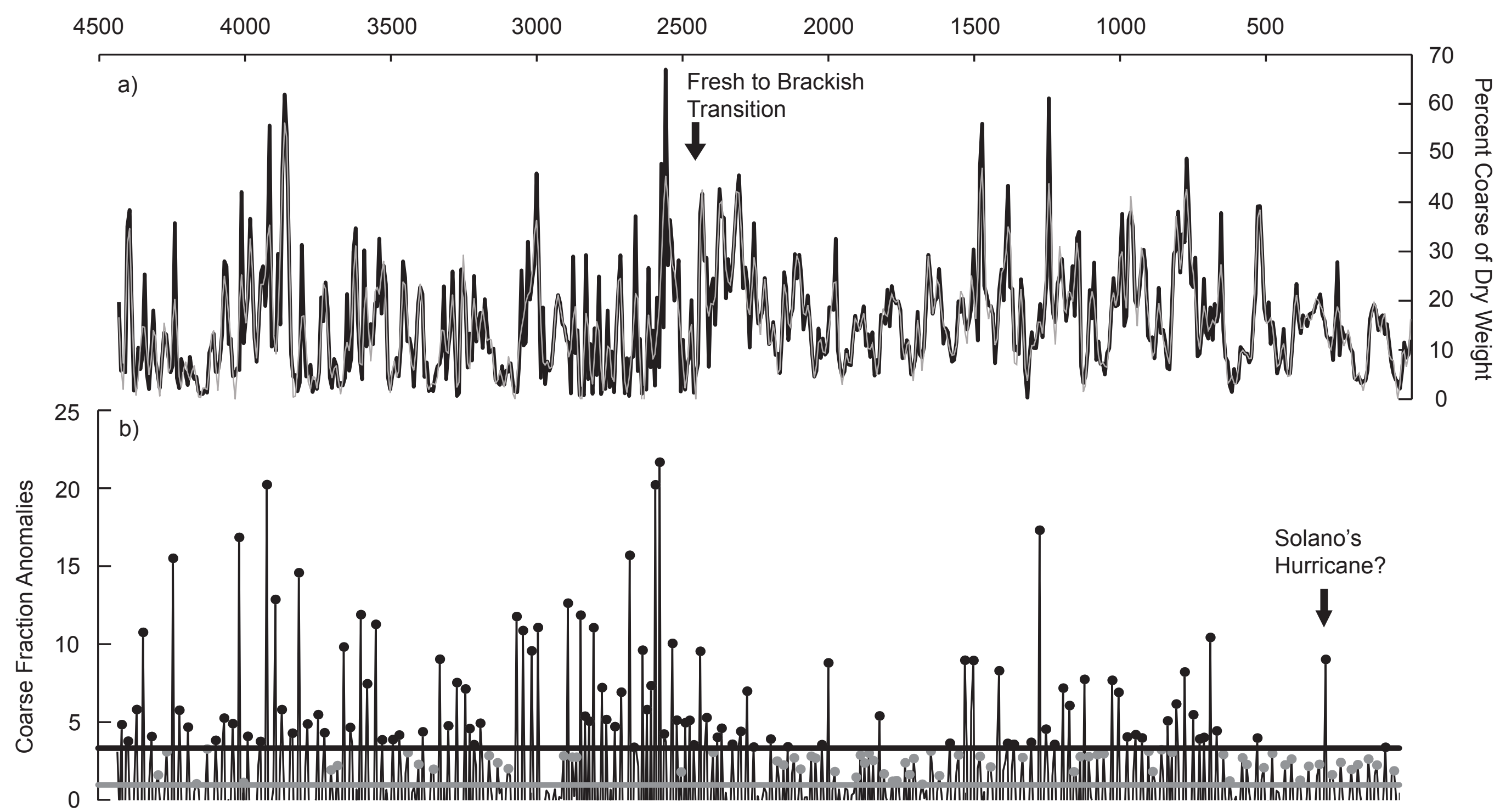

c)

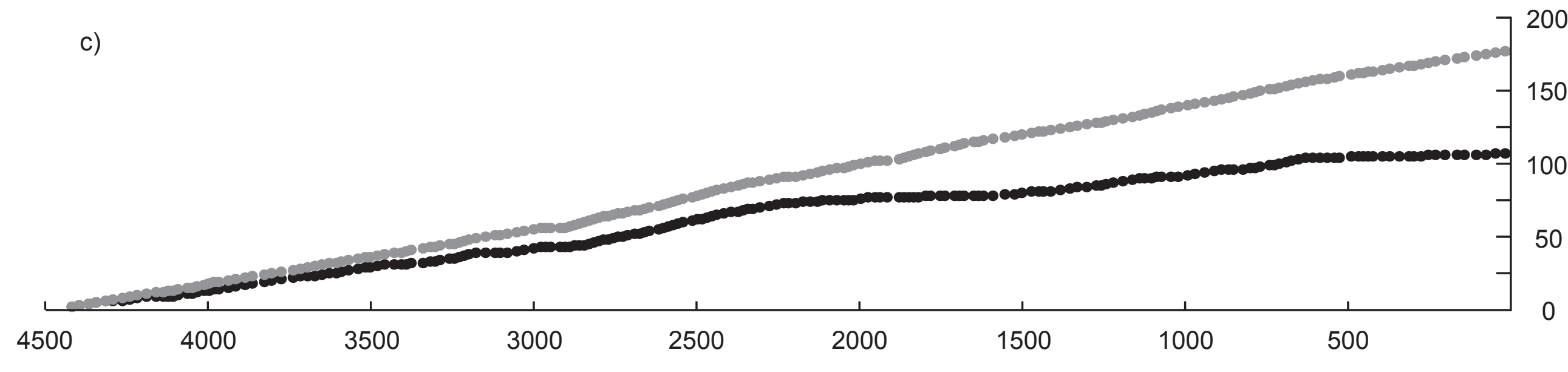

Cal. Yrs. B.P

Figure 6 - Identification of paleohurricanes in MLTI. Panel (a) shows the raw coarse fraction time series from MLTI (solid black) with the thinner, gray line outlining the low-frequency, (> 30 year) background variability of the time series. The horizon of the fresh to brackish transition, as suggested by a shift in the coarse fraction, inorganic content and microfossil assemblages, is indicated by a black arrow. Panel (b) displays the corresponding coarse fraction anomalies, which represent the high-frequency $(<30$ year) variability of the raw time series. 177 anomaly values (gray circles) exceeded the low threshold (LT, gray line) and 107 anomaly values (black circles) exceeded the high threshold (HT, black line). The coarse fraction anomaly that may be associated with Solano's Hurricane of I780 A.D. is identified. Panel (c) shows the cumulative number of LT (gray) and HT (black) events with time. The slope of the cumulative function is equal to the frequency of storm events. 
Cal. Yrs. B.P.

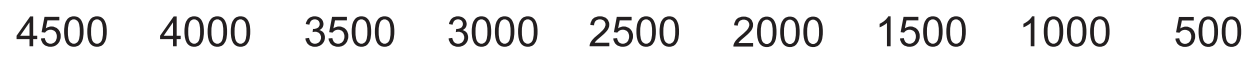

a)
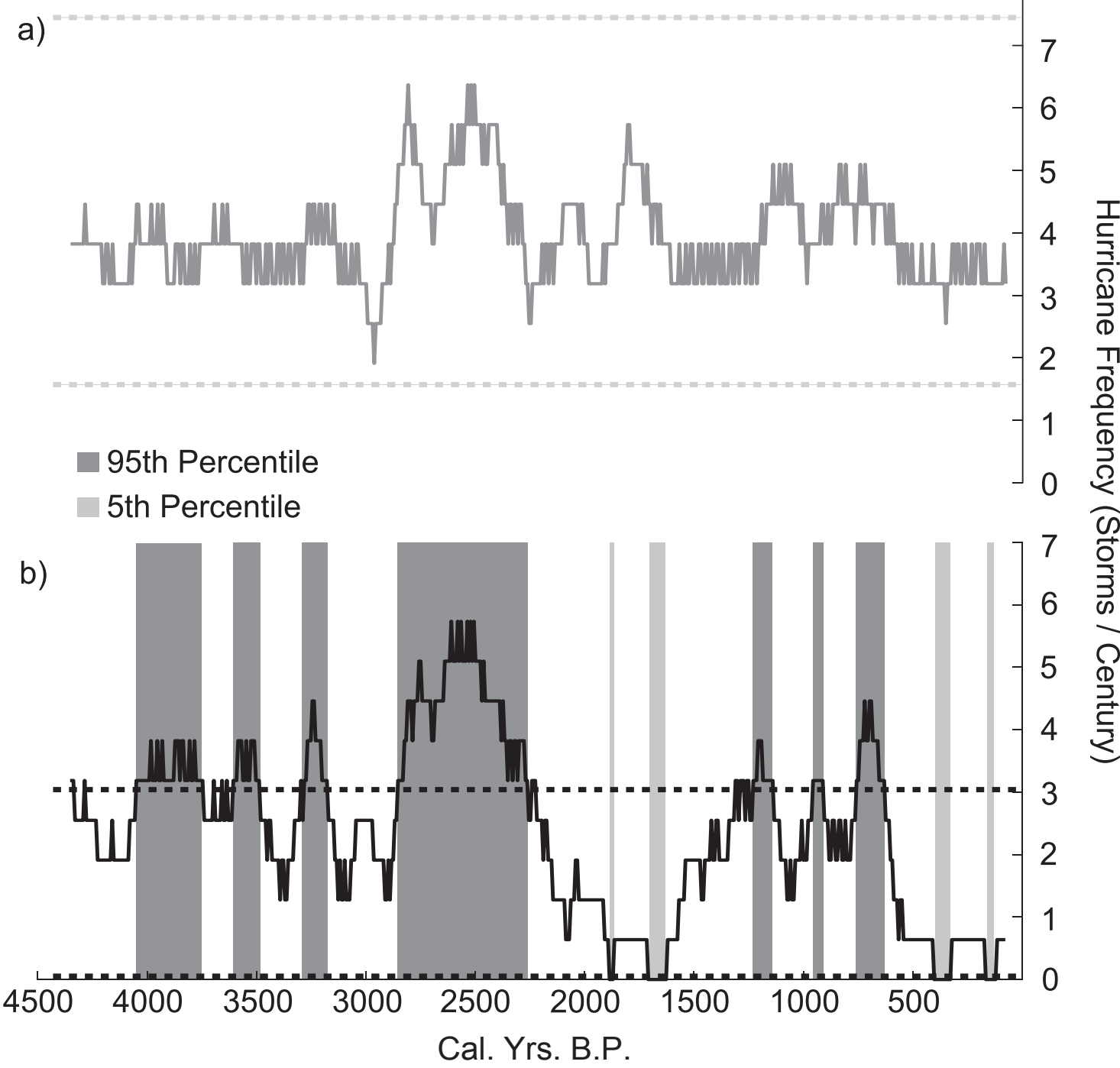

Figure 7 - Local storm frequency through time. Panel (a) is the MLTI time series of hurricane frequency normalized to events per century (gray curve) when all coarse fraction anomalies exceeding the $\mathrm{LH}$ were attributed to storms. Due to truncation required by the I57-year sliding window, the time series spans the period from 4294 to 21 cal. yrs. BI950A.D.. The dashed gray lines represent the 95th (upper line, $~ 7.5$ storms per century) and 5th (lower line, $\sim 1.7$ storms per century) percentiles of storm frequency assuming a Poisson rate of 3.8 storms per century, which is the mean rate of LT events during the 157-year historic period. Panel (b) is the same analysis, but only coarse fraction anomalies exceeding the HT were attributed to storms. In this case, the mean frequency of HT events during the historic period was 0.6 storms per century, and the dashed black lines represent the 95 th (upper line, $\sim 3.0$ storms per century) and 5 th (lower line, $\sim 0.03$ storms per century) percentiles of storm frequency based on a Poisson rate equal to the historic rate. Darker gray shaded portions of panel (b) highlight periods when HT storm frequency was significantly higher than the historic rate. The lighter gray periods were less active times in the record when HT storm frequency was significantly lower than the historic rate. 
Cal. Yrs. B.P.

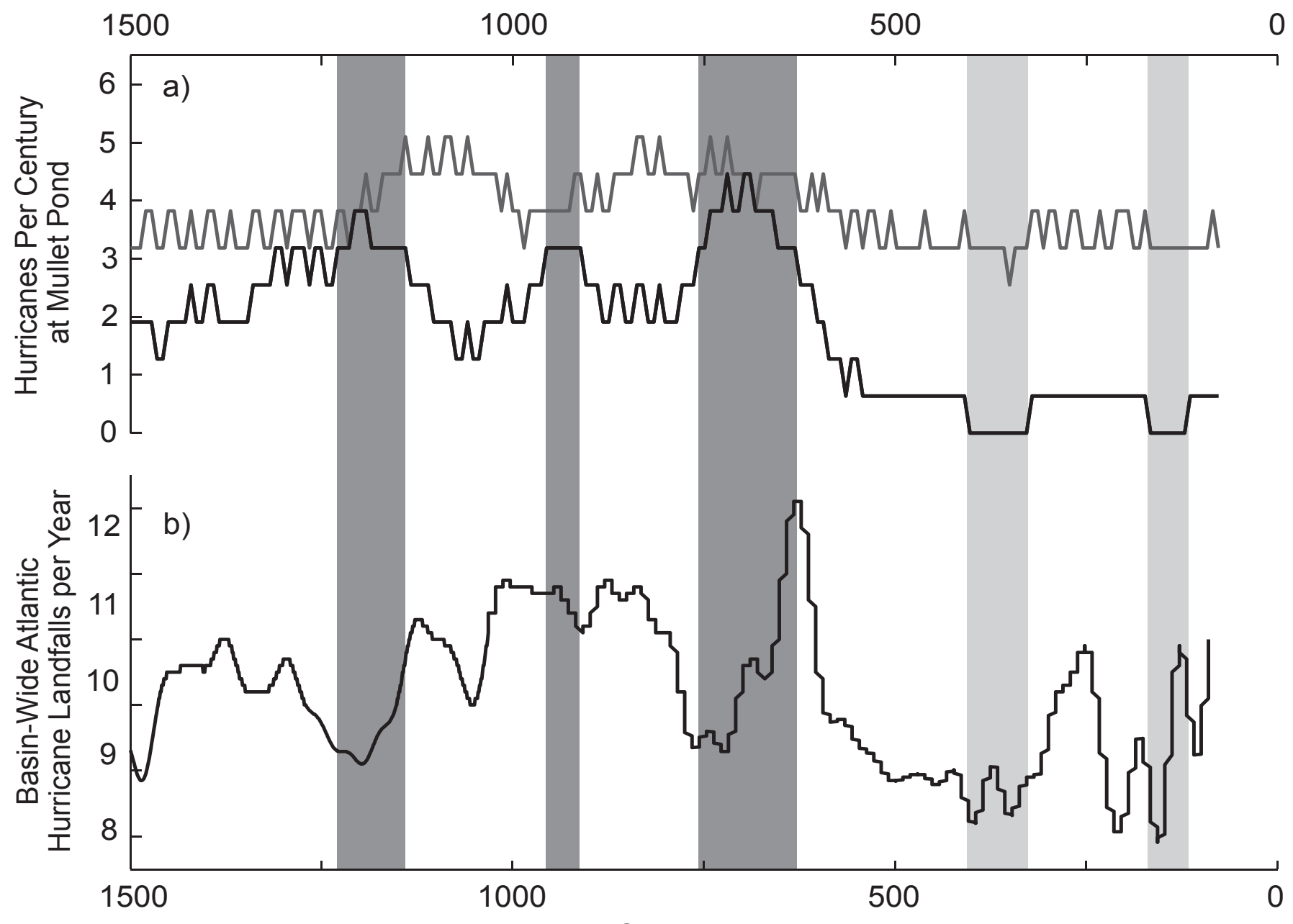

Cal. Yrs. B.P.

Figure 8 - Comparison of MLTI record with Mann et al. 2009 Atlantic Basin paleohurricane record compilation. Panel (a) is the time series of hurricane frequency at Mullet Pond from I500 to 21 cal. yrs. BI950A.D.. The gray curve is the LT time series and the black curve is the HT time series. The darker gray shaded portion highlights a period with storm frequency that exceeded the 95th percentile of what would be expected assuming a Poisson rate assigned by the historic portion of the MLTI paleohurricane record. The period shaded in light gray saw fewer hurricanes with storm frequency in the bottom 5 th percentile of what would be expected assuming the historic rate. Panel (b) is a reconstruction of annual basin-wide Atlantic hurricane landfalls based on a composite of various paleohurricane reconstructions from the Caribbean, U.S. East Coast and the northern Gulf of Mexico for the period 1450 - 100 yrs. BI950A.D. (Mann et al. 2009). 


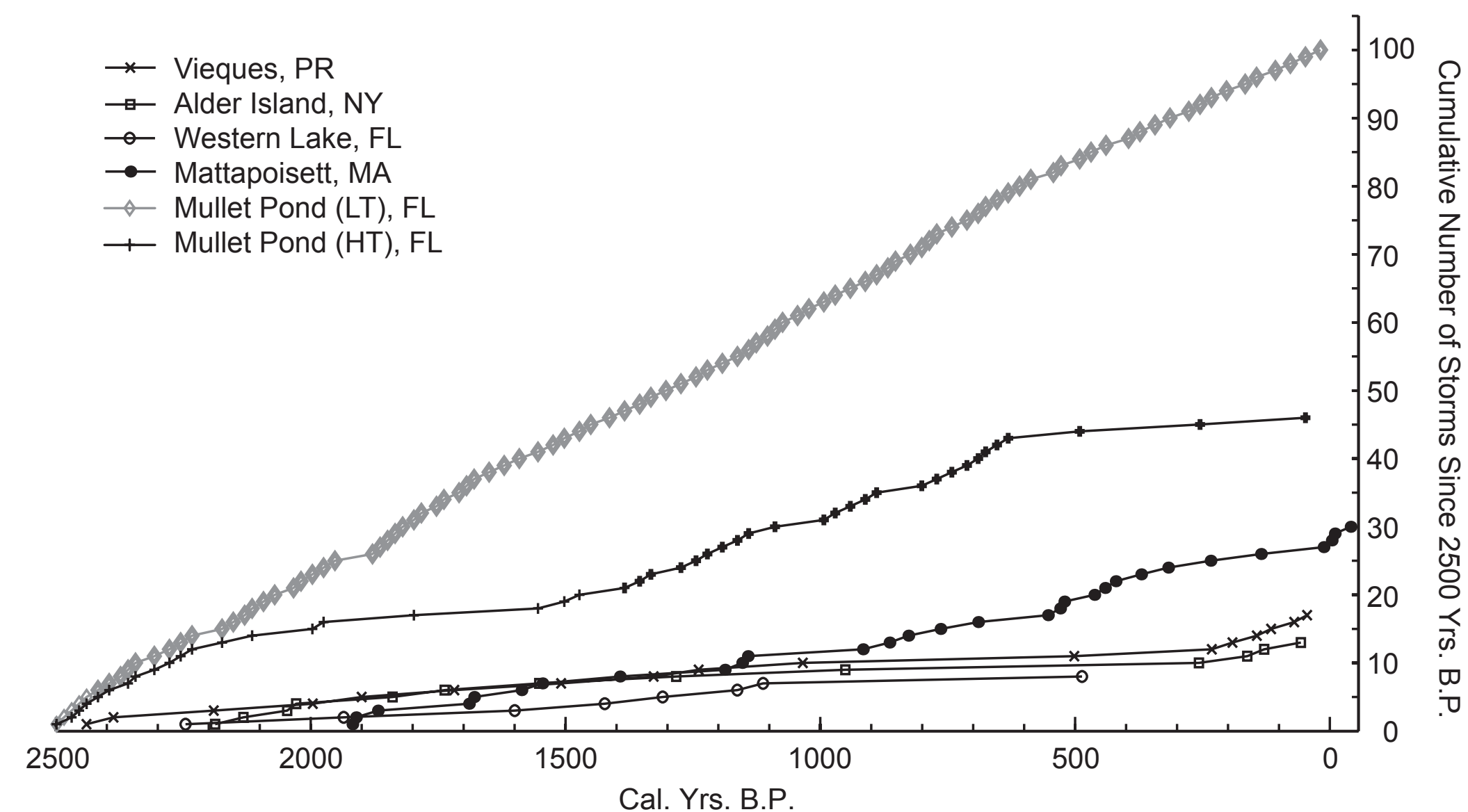

Figure 9 - Comparison of MLTI record with other paleohurricane records. Plot of the cumulative number of storms since 2500 cal. yrs. B.P. detected in paleohurricane records from the Caribbean, the Northeastern United States, and the northern Gulf of Mexico. Records from Laguna Playa Grande in Vieques, Puerto Rico (x) (Donnelly and Woodruff 2007), Alder Island in New York ( $\square$ ) (Scileppi and Donnelly 2007),Western Lake in Florida ( $\square$ ) (Liu and Fearn 2000), and Mattapoisett Marsh in Massachusetts ( $\square$ ) (Boldt et al. 2010) are shown alongside the LT $(\square)$ and HT (+) versions of the MLTI record. 
Table 1 - Dominant foraminifera in surface samples along depth transect

\begin{tabular}{|c|c|c|c|c|}
\hline Elevation $(m)^{*}$ & Distance $(\mathbf{k m})^{* *}$ & $\begin{array}{c}\text { Ochlokonee Bay } \\
\\
\text { Start: } 29.9612^{\circ} \mathrm{N} \\
84.3852^{\circ} \mathrm{W} \\
0 \mathrm{~m} \mathrm{MSL} \\
\text { End: } 29.9623^{\circ} \mathrm{N} \\
84.3806^{\circ} \mathrm{W} \\
-2.3 \mathrm{~m} \mathrm{MSL}\end{array}$ & $\begin{array}{c}\text { Gulf of Mexico } \\
\text { Transect } \mathbf{1}^{\mathrm{a}} \\
\text { Start: } 29.9281^{\circ} \mathrm{N} \\
84.4565^{\circ} \mathrm{W} \\
-0.8 \mathrm{~m} \mathrm{MSL} \\
\text { End: } 29.7554^{\circ} \mathrm{N} \\
84.5108^{\circ} \mathrm{W} \\
-12.0 \mathrm{~m} \mathrm{MSL}\end{array}$ & 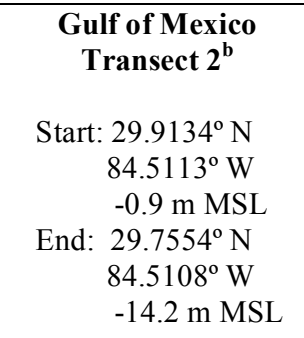 \\
\hline 3 to $-1 \mathrm{~m}$ & $+0.1^{\dagger}$ to $0.4 \mathrm{~km}$ & barren & barren & barren \\
\hline-1 to $-5 \mathrm{~m}$ & 0.4 to $5 \mathrm{~km}$ & $\begin{array}{l}\text { Ammobaculites dilatus } \\
\text { Ammobaculites exiguus } \\
\text { Ammobaculites salsum } \\
\text { Ammonia beccarri } \\
\text { Elphidium spp. } \\
\text { Milliammina fusca }\end{array}$ & $\begin{array}{l}\text { Ammonia beccari } \\
\text { Amphistegina spp. } \\
\text { Quinqueloculina spp. }\end{array}$ & $\begin{array}{l}\text { Ammonia beccarri } \\
\text { Amphistegina spp. } \\
\text { Rosalina spp. }\end{array}$ \\
\hline-5 to $-10 \mathrm{~m}$ & 5 to $16 \mathrm{~km}$ & & $\begin{array}{l}\text { Ammonia beccari } \\
\text { Amphistegina spp. } \\
\text { Astacolus crepidulus } \\
\text { Brizalina spathulata } \\
\text { Elphidium spp. } \\
\text { Fursenkoina fusiformis } \\
\text { planktonics } \\
\text { Quinqueloculina spp. } \\
\text { Rosalina spp. }\end{array}$ & $\begin{array}{l}\text { Ammobaculites exiguus } \\
\text { Ammonia beccari } \\
\text { Amphistegina spp. } \\
\text { Astacolus crepidulus } \\
\text { Brizalina spathulata } \\
\text { Buccella frigida } \\
\text { Elphidium spp. } \\
\text { Fursenkoina fusiformis } \\
\text { planktonics } \\
\text { Quinqueloculina spp. } \\
\text { Rosalina spp. }\end{array}$ \\
\hline-10 to $-15 \mathrm{~m}$ & 16 to $21 \mathrm{~km}$ & & $\begin{array}{l}\text { Ammonia spp. } \\
\text { Astacolus crepidulus } \\
\text { Cibicides lobatulus } \\
\text { Elphidium spp. } \\
\text { planktonics } \\
\text { Quinqueloculina spp. } \\
\text { Rosalina spp. }\end{array}$ & $\begin{array}{l}\text { Ammonia spp. } \\
\text { Astacolus crepidulus } \\
\text { Cibicides lobatulus } \\
\text { Elphidium spp. } \\
\text { planktonics } \\
\text { Quinqueloculina spp. } \\
\text { Rosalina spp. } \\
\text { Textularia agglutinans }\end{array}$ \\
\hline
\end{tabular}

* represents approximate elevation relative to MSL in meters

** represents approximate distance from MSL in kilometers

$\dagger$ inland dune ridge samples

${ }^{\text {a }}$ Transect 1 lies $12 \mathrm{~km}$ west of Bald Point

${ }^{\mathrm{b}}$ Transect 2 lies $16 \mathrm{~km}$ west of Bald Point 
Table 2 - Provenance of foraminiferal assemblages in core samples

\begin{tabular}{|c|c|c|c|c|}
\hline Core & Depth (cm) & $\begin{array}{l}\text { Approximate Cal. } \\
\text { Age (Yrs. B } \text { 1950A.D.) }\end{array}$ & $\begin{array}{c}\text { Foraminifera } \\
\text { Assemblage } \\
\text { Source Depth (m } \\
\text { MSL) } \\
\end{array}$ & $\begin{array}{c}\text { Modern Shore-to- } \\
\text { Source Distance } \\
(\mathbf{k m})\end{array}$ \\
\hline $\operatorname{MLT} 1^{\mathrm{a}}$ & $0.5 \mathrm{~cm} \pm 0.5 \mathrm{~cm}$ & - 55 yrs. (2005 A.D.)* & Endemic $* *$ & $0.0 \mathrm{~km}$ \\
\hline $\operatorname{MLT} 1^{b}$ & $2 \mathrm{~cm} \pm 1 \mathrm{~cm}$ & - 48 yrs. (1998 A.D.)* & -1 to $-5 \mathrm{~m}$ & 0.4 to $5 \mathrm{~km}$ \\
\hline $\operatorname{MLT} 1^{b}$ & $4 \mathrm{~cm} \pm 0.5 \mathrm{~cm}$ & - 37 yrs. (1987 A.D.)* & $>-5 \mathrm{~m}$ & $>5 \mathrm{~km}$ \\
\hline $\operatorname{MLT} 1^{b}$ & $12 \mathrm{~cm} \pm 0.5 \mathrm{~cm}$ & 6 yrs. (1944 A.D.)* & -1 to $-5 \mathrm{~m}$ & 0.4 to $5 \mathrm{~km}$ \\
\hline $\operatorname{MLT} 1^{b}$ & $16 \mathrm{~cm} \pm 1.0 \mathrm{~cm}$ & 29 yrs. (1921 A.D.)* & -5 to $-10 \mathrm{~m}$ & 5 to $16 \mathrm{~km}$ \\
\hline $\operatorname{MLT} 1^{b}$ & $20 \mathrm{~cm} \pm 1.0 \mathrm{~cm}$ & 53 yrs. (1897 A.D.)* & -5 to $-10 \mathrm{~m}$ & 5 to $16 \mathrm{~km}$ \\
\hline $\operatorname{MLT} 1^{b}$ & $34 \mathrm{~cm} \pm 2.0 \mathrm{~cm}$ & 140 yrs. (1810 A.D.)* & -1 to $-5 \mathrm{~m}$ & 0.4 to $5 \mathrm{~km}$ \\
\hline $\operatorname{MLT} 1^{b}$ & $39 \mathrm{~cm} \pm 0.5 \mathrm{~cm}$ & 172 yrs. (1778 A.D.)* & $>-5 \mathrm{~m}$ & $>5 \mathrm{~km}$ \\
\hline $\operatorname{MLT} 1^{a}$ & $52 \mathrm{~cm} \pm 0.5 \mathrm{~cm}$ & 326 yrs. & Endemic $* *$ & $0.0 \mathrm{~km}$ \\
\hline $\operatorname{MLT} 1^{\mathrm{a}}$ & $130 \mathrm{~cm} \pm 0.5 \mathrm{~cm}$ & 902 yrs. & Endemic $* *$ & $0.0 \mathrm{~km}$ \\
\hline $\operatorname{MLT} 1^{\mathrm{a}}$ & $234 \mathrm{~cm} \pm 0.5 \mathrm{~cm}$ & 1670 yrs. & Endemic $* *$ & $0.0 \mathrm{~km}$ \\
\hline $\operatorname{MLT} 1^{b}$ & $292 \mathrm{~cm} \pm 0.5 \mathrm{~cm}$ & 2098 yrs. & -5 to $-10 \mathrm{~m}$ & 5 to $16 \mathrm{~km}$ \\
\hline $\operatorname{MLT} 1^{a}$ & $340 \mathrm{~cm} \pm 0.5 \mathrm{~cm}$ & 2452 yrs. & Barren & NA \\
\hline $\operatorname{MLT} 1^{a}$ & $427 \mathrm{~cm} \pm 0.5 \mathrm{~cm}$ & 3094 yrs. & Barren & NA \\
\hline $\operatorname{MLT} 1^{a}$ & $542 \mathrm{~cm} \pm 0.5 \mathrm{~cm}$ & 3943 yrs. & Barren & NA \\
\hline $\operatorname{MLT} 1^{a}$ & $601 \mathrm{~cm} \pm 0.5 \mathrm{~cm}$ & 4379 yrs. & Barren & NA \\
\hline $\operatorname{MLT} 2^{b}$ & $431 \mathrm{~cm} \pm 0.5 \mathrm{~cm}$ & 3667 yrs. & -5 to $-10 \mathrm{~m}$ & 5 to $16 \mathrm{~km}$ \\
\hline $\operatorname{MLT} 2^{b}$ & $504 \mathrm{~cm} \pm 0.5 \mathrm{~cm}$ & 4996 yrs. & -1 to $-5 \mathrm{~m}$ & 0.4 to $5 \mathrm{~km}$ \\
\hline $\operatorname{MLT} 2^{b}$ & $510 \mathrm{~cm} \pm 0.5 \mathrm{~cm}$ & 5105 yrs. & -1 to $-5 \mathrm{~m}$ & 0.4 to $5 \mathrm{~km}$ \\
\hline $\operatorname{MLT} 2^{b}$ & $531 \mathrm{~cm} \pm 0.5 \mathrm{~cm}$ & 5487 yrs. & -1 to $-5 \mathrm{~m}$ & 0.4 to $5 \mathrm{~km}$ \\
\hline $\operatorname{MLT} 2^{c}$ & $604 \mathrm{~cm} \pm 0.5 \mathrm{~cm}$ & 7740 yrs. & Barren & NA \\
\hline $\operatorname{MLT} 2^{d}$ & $617 \mathrm{~cm} \pm 0.5 \mathrm{~cm}$ & 8180 yrs. & Barren & NA \\
\hline
\end{tabular}

\footnotetext{
${ }^{\text {a }}$ Sampled away from coarse layers, ${ }^{\mathrm{b}}$ Sampled at coarse layer, ${ }^{\mathrm{c}}$ Sampled from peat, ${ }^{\mathrm{d}}$ Sampled from coarse basal sand unit

* Approximate age calculated from mean sample depth and polynomial, historic age model for upper MLT1

** Endemic, core top assemblage (-2.3 m MSL): Ammobaculites sp., Arenoparella mexicana, Jadammina macrescens, and Tiphotrocha comprimata.
} 
Table 3 - Mullet 1 Radiocarbon Calibration

\begin{tabular}{|c|c|c|c|c|c|c|c|}
\hline Lab No. & Core & Depth $(\mathrm{cm})$ & ${ }^{14} \mathrm{C}$ Age & $\begin{array}{c}1 \sigma \text { Calendar Ages } \\
\text { In Years } B_{1950} \\
\text { (Probability) }\end{array}$ & $\begin{array}{c}2 \sigma \text { Calendar Ages } \\
\text { In Years } B_{1950} \\
\text { (Probability) }\end{array}$ & $\begin{array}{c}\text { Cal. Age } \\
(\text { Years B } 1950)\end{array}$ & Material Dated \\
\hline OS-69342 & MLT 1 & 80 & $545 \pm 25$ & $\begin{array}{l}\mathbf{5 2 8}-554(0.795) \\
610-621(0.205)\end{array}$ & $\begin{array}{l}518-560(0.685) \\
599-631(0.315)\end{array}$ & 541 & plant fragments \\
\hline OS-68382 & MLT 1 & $177-178$ & $1300 \pm 20$ & $\begin{array}{l}1185-1203(0.355) \\
1243-1249(0.087) \\
1256-1281(0.558)\end{array}$ & $\begin{array}{l}1179-1211(0.335) \\
1226-1287(0.665)\end{array}$ & 1269 & plant fragments \\
\hline OS-68469 & MLT 1 & 245 & $1830 \pm 30$ & 1732-1814 (1.000) & $\begin{array}{l}1698-1830(0.964) \\
1843-1864(0.036)\end{array}$ & 1773 & wood \\
\hline OS-68381 & MLT 1 & $268-269$ & $1790 \pm 20$ & $\begin{array}{l}\mathbf{1 6 3 2}-1650(0.171) \\
1693-1738(0.734) \\
1761-1773(0.096)\end{array}$ & $\begin{array}{l}1627-1659(0.164) \\
1661-1666(0.009) \\
1691-1813(0.827)\end{array}$ & $1716^{*}$ & wood \\
\hline OS-64468 & MLT 1 & 290 & $2130 \pm 30$ & 2056-2151 (1.000) & $\begin{array}{l}2001-2158(0.890) \\
2259-2298(0.110)\end{array}$ & 2104 & wood \\
\hline OS-68476 & MLT 1 & $298-299$ & $2170 \pm 30$ & $\begin{array}{l}\mathbf{2 1 2 4}-2160(0.349) \\
2170-2177(0.061) \\
2245-2301(0.590)\end{array}$ & $\begin{array}{l}2065-2084(0.029) \\
2106-2214(0.462) \\
2218-2311(0.509)\end{array}$ & 2273 & wood \\
\hline OS-69529 & MLT 1 & 353 & $2500 \pm 30$ & $\begin{array}{l}\mathbf{2 4 9 7 - 2 5 9 7}(0.700) \\
2612-2622(0.073) \\
2629-2638(0.066) \\
2688-2713(0.161)\end{array}$ & $2468-2730(1.000)$ & 2547 & plant fragments \\
\hline OS-69546 & MLT 1 & 422 & $2910 \pm 60$ & $\begin{array}{l}\mathbf{2 9 6 2}-3084(0.674) \\
3088-3145(0.279) \\
3147-3157(0.047)\end{array}$ & $\begin{array}{l}2878-2913(0.042) \\
2917-3242(0.958)\end{array}$ & 3053 & wood \\
\hline OS-69343 & MLT 1 & 478 & $3200 \pm 35$ & 3386-3447 (1.000) & $3358-3479(1.000)$ & 3417 & plant fragments \\
\hline OS-69344 & MLT 1 & 499 & $3350 \pm 35$ & $\begin{array}{l}\text { 3490-3495 }(0.035) \\
3510-3519(0.061) \\
3556-3639(0.904)\end{array}$ & $\begin{array}{l}3479-3644(0.923) \\
3659-3686(0.077)\end{array}$ & 3598 & wood \\
\hline OS-64467 & MLT 1 & 569 & $3800 \pm 35$ & $\begin{array}{l}4100-4114(0.106) \\
4147-4239(0.894)\end{array}$ & $\begin{array}{l}4013-4020(0.005) \\
4083-4297(0.974) \\
4330-4351(0.018) \\
4373-4379(0.004)\end{array}$ & 4193 & wood \\
\hline
\end{tabular}

${ }^{*}$ Cal. age omitted from age model as it is younger than would be expected based on other ${ }^{14} \mathrm{C}$ dates in the sequence.

Black bold values are $1 \sigma$ max. uncertainties and gray bold values are $2 \sigma$ max. uncertainties. 
Table 4 - Mullet 2 Radiocarbon Calibration

\begin{tabular}{|c|c|c|c|c|c|c|c|}
\hline Lab No. & Core & $\begin{array}{c}\text { Depth } \\
(\mathrm{cm})\end{array}$ & ${ }^{14} \mathrm{C}$ Age & $\begin{array}{c}\text { 1o Calendar Ages } \\
\text { In Years B }{ }_{1950} \\
\text { (Probability) }\end{array}$ & $\begin{array}{c}2 \sigma \text { Calendar Ages } \\
\text { In Years B }{ }_{1950} \\
\text { (Probability) }\end{array}$ & $\begin{array}{c}\text { Cal. Age } \\
\left(\text { Years B }{ }_{1950}\right)\end{array}$ & Material Dated \\
\hline OS-74406 & MLT 2 & 155 & $1260 \pm 25$ & $\begin{array}{l}1176-1187(0.156) \\
1200-1259(0.844)\end{array}$ & $\begin{array}{l}1093-1106(0.014) \\
1137-1161(0.050) \\
1168-1279(0.936)\end{array}$ & 1230 & tree bark \\
\hline OS-71342 & MLT 2 & 270 & $2210 \pm 15$ & $\begin{array}{l}\mathbf{2 1 5 6}-2184(0.349) \\
2193-2206(0.129) \\
2231-2266(0.406) \\
2297-2307(0.116)\end{array}$ & $\begin{array}{l}2153-2278(0.860) \\
2288-2312(0.140)\end{array}$ & 2249 & plant fragments \\
\hline OS-74405 & MLT 2 & 415 & $3130 \pm 35$ & $\begin{array}{l}\text { 3274-3281 (0.068) } \\
3333-3393(0.932)\end{array}$ & $\begin{array}{l}3263-3311(0.161) \\
3316-3414(0.786) \\
3421-3443(0.053)\end{array}$ & 3363 & plant fragments \\
\hline OS-71863 & MLT 2 & 542 & $4890 \pm 240$ & $\begin{array}{l}\mathbf{5 3 2 4}-5415(0.140) \\
5443-5907(0.860)\end{array}$ & $\begin{array}{l}4976-5015(0.010) \\
5032-6186(0.990)\end{array}$ & 5675 & plant fragments / wood \\
\hline OS-71343 & MLT 2 & 616 & $7120 \pm 20$ & 7938-7965 (1.000) & $\begin{array}{l}7875-7891(0.065) \\
7930-7982(0.919) \\
7989-7997(0.016)\end{array}$ & 7952 & plant fragments \\
\hline
\end{tabular}

Black bold values are $1 \sigma$ max. uncertainties and gray bold values are $2 \sigma$ max. uncertainties. 
Cal. Yrs. BP

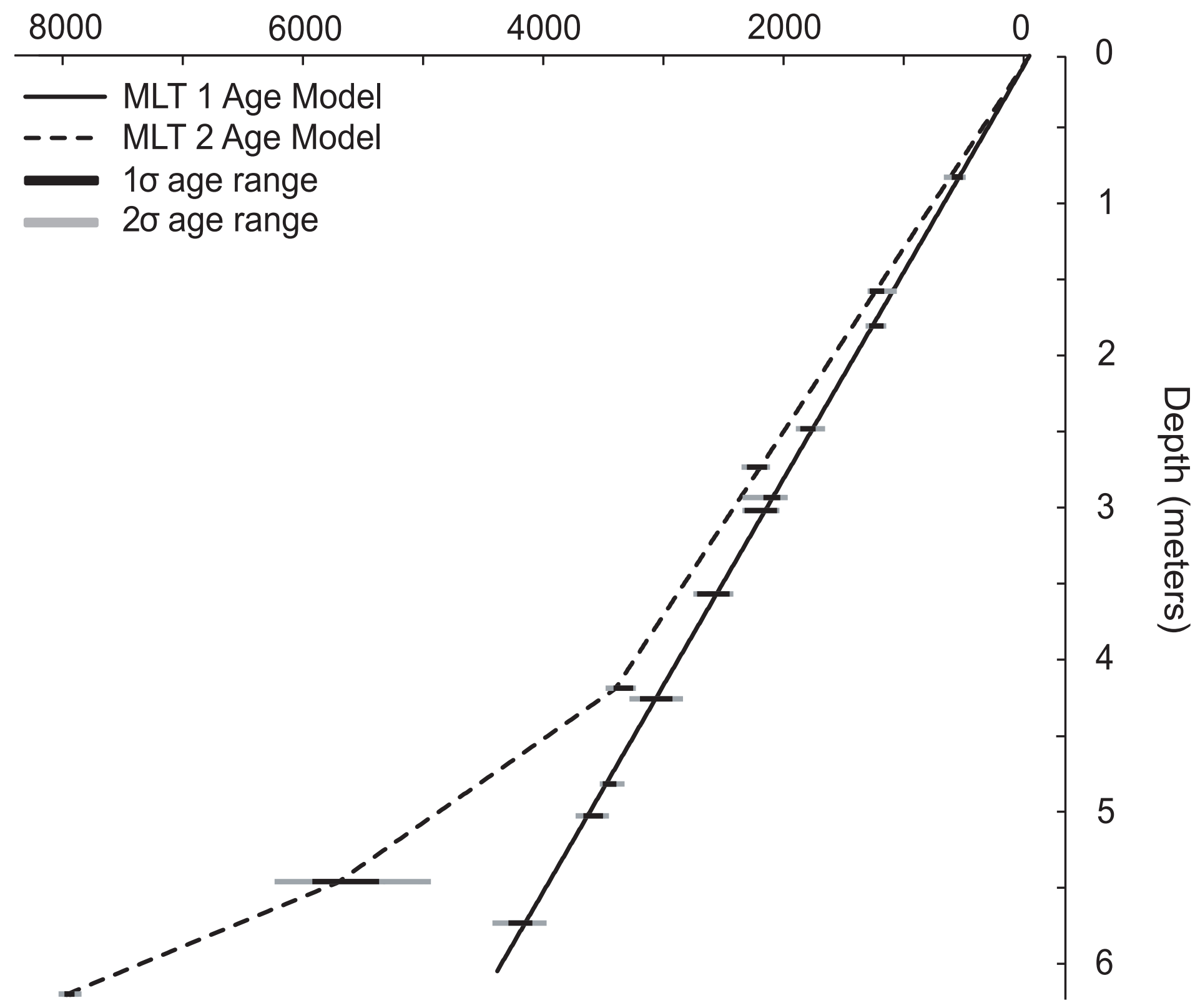

Supplementary Figure I - MLTI and MLT2 radiocarbon-based age models. Ten radiocarbon-based calendar age ranges for terrestrial plant fragments taken from MLTI and five from MLT2 are plotted versus the depths from which they were collected in each core. Calendar ages and ranges in years before 1950 A.D. were found from I4C ages and uncertainties using the IntCal09 calibration dataset in the Calib6 program (Reimer et al. 2009). See Tables 3 and 4 for details. A single linear model (solid black line) was fit to the MLTI ages and three different linear models (dashed black lines) were fit to the MLT2 ages. 


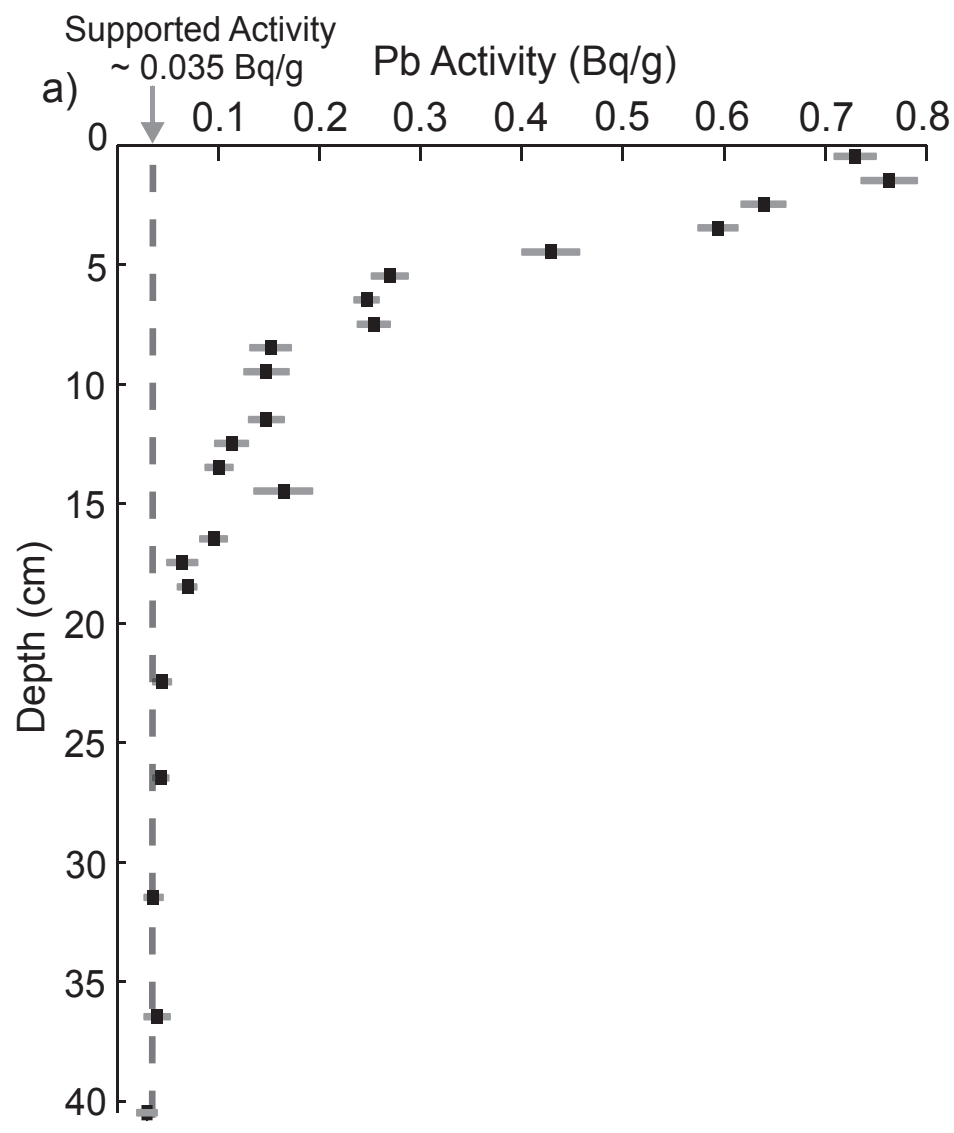

b)

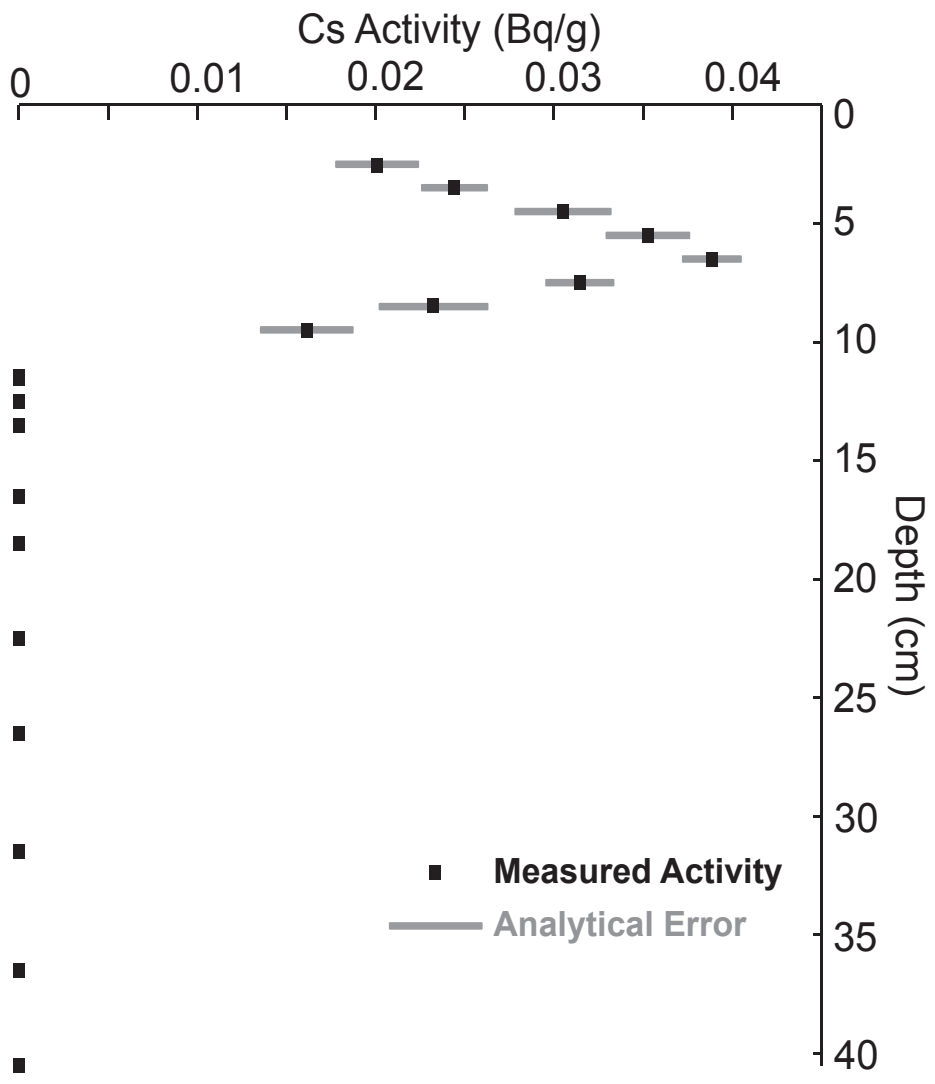

Supplementary Figure 2 - MLTI $210 \mathrm{~Pb}$ and $137 \mathrm{Cs}$ data. Panel $(\mathrm{a})$ is the vertical profile of $210 \mathrm{~Pb}$ activity in the uppermost $40 \mathrm{~cm}$ of MLTI. Below about $20 \mathrm{~cm}$ depth, all $210 \mathrm{~Pb}$ activity appeared to be supported by the sediment itself at a level of approximately $0.035 \mathrm{~Bq} / \mathrm{g}$ (gray dashed line). Panel (b) is the vertical profile of I37Cs activity in the uppermost $40 \mathrm{~cm}$ of MLTI. The initial detection and subsequent peak of I37Cs associated with the advent of ( 1954 A.D.) and moratorium on ( 1963 A.D.) atmospheric nuclear weapons were detected at 9.5 and $6.5 \mathrm{~cm}$ depth respectively. In both panel (a) and (b), the black squares represent the measured values, and the gray bars are the analytical uncertainty in those measurements. 


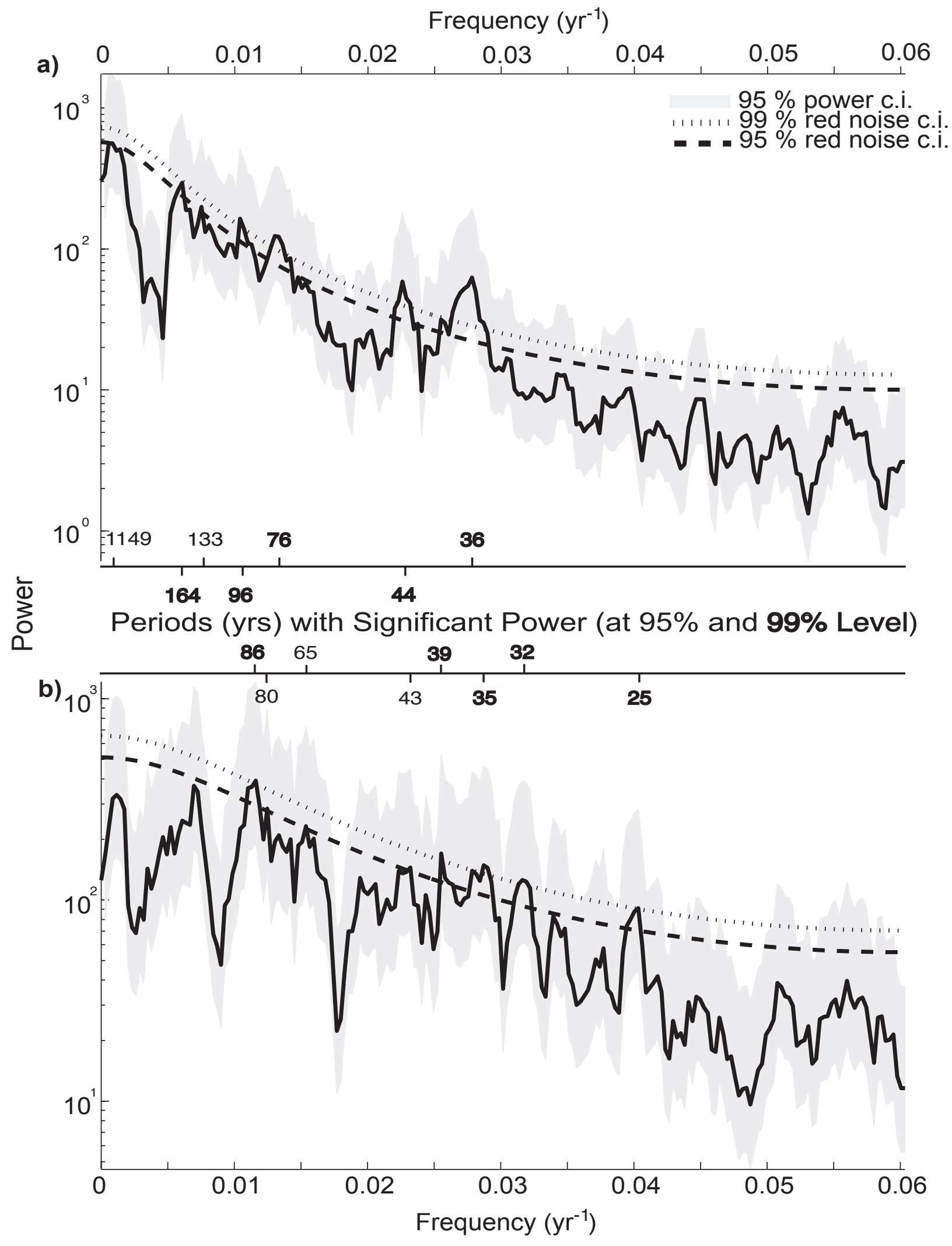

Supplementary Figure 3 - Power spectra of MLT2 inorganics and coarse fraction time series. Panel (a) shows the power spectrum of the MLT2 time series of percent inorganics. The solid, black curve is the power calculated for each frequency bin and the gray shading is the 95 percent confidence interval of that power calculation. The dashed and dotted curves are the 95 and 99 percent confidence intervals for a comparable red noise power spectrum. Periods (in years) corresponding to frequencies with calculated power exceeding the 95 and 99 percent red noise confidence intervals are labeled in regular and bold fonts respectively. Panel (b) shows the same analysis for the MLT2 time series of sand content by weight ( $>63 \mu \mathrm{m})$. 

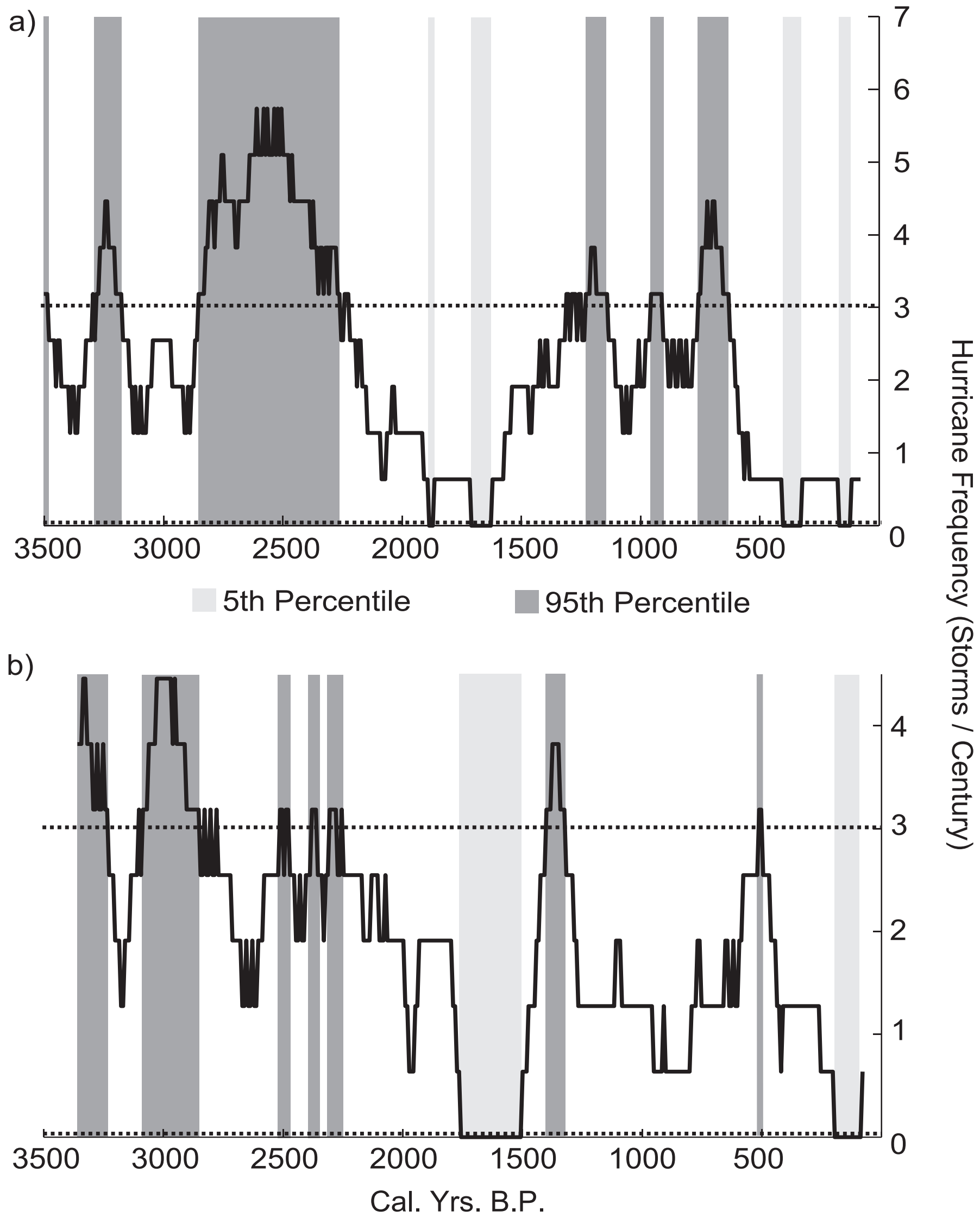

Supplementary Figure 4 - MLTI and MLT2 storm frequency time series comparison. Panel (a) is the MLTI time series of hurricane frequency normalized to events per century as described in Figure 7. Panel (b) is the time series of hurricane frequency attained by applying the same process and HT value to the MLT2 record. Darker gray shaded portions of both panels highlight periods with HT storm frequency that exceeded the upper bound of the 95 percent confidence interval, assuming a Poisson process with a mean rate equal to the historic rate. The lighter gray periods were less active times in the record when storm frequency was below the lower bound of the confidence interval. 
Cal. Yrs. B.P.
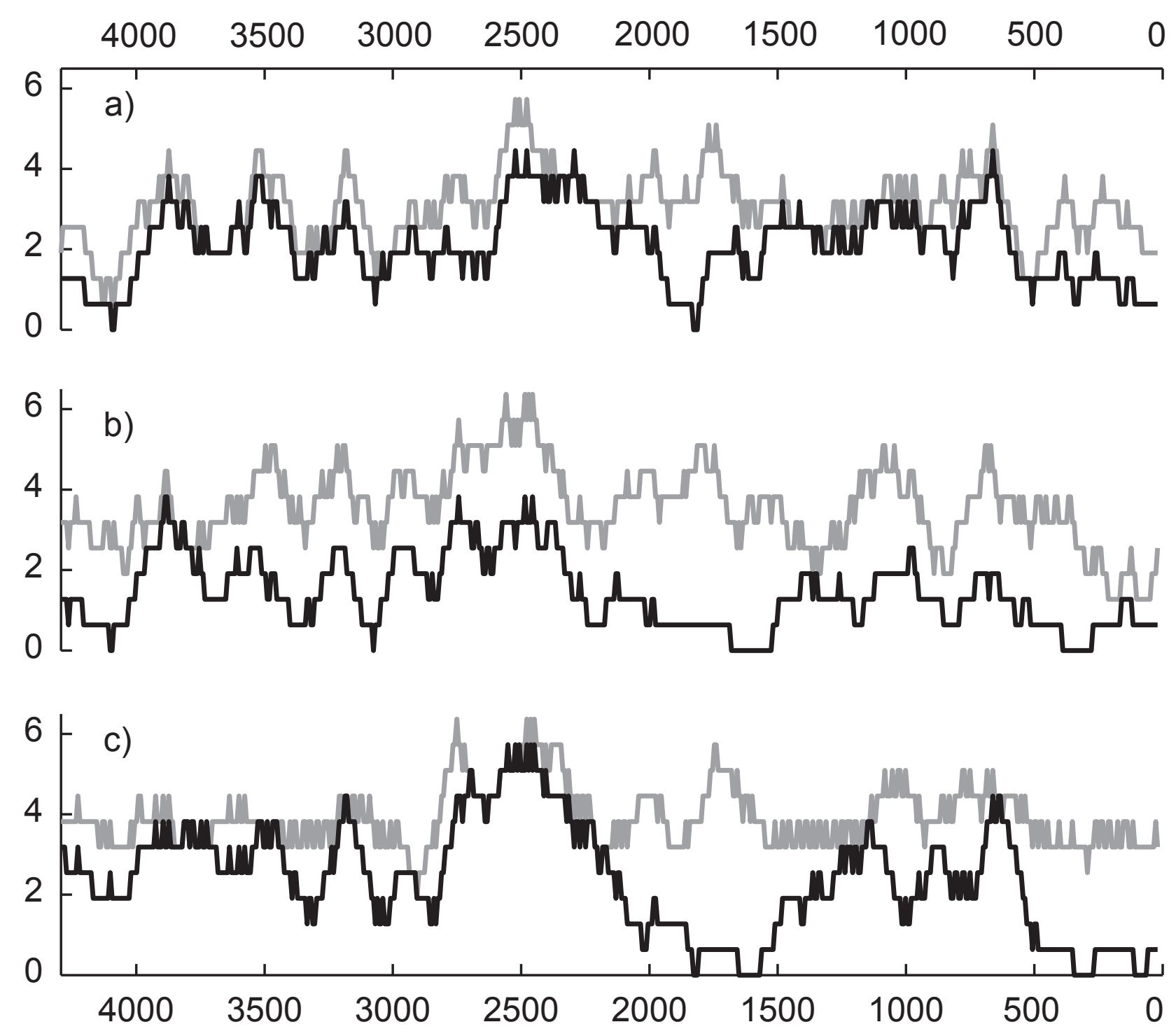

Cal. Yrs. B.P.

Supplemental Figure 5 -Alternate storm frequency time series by data filtering method. Two alternate time series were produced to evaluate the sensitivity of the storm frequency time series to the filtering method applied to the raw data. Panel (a) is the plot of the frequency of hurricanes through time that results from applying a 157-year sliding window to the raw coarse fraction data. Under this method, the data are not filtered and the historically-derived LT and HT values (from Figure 6a, I I.52 and 19.23 percent coarse of dry weight, respectively) were associated with Hurricane Elena (I985 A.D.) and the I894/1896 A.D. hurricanes, respectively. Applying these thresholds for storm detection to the raw MLTI coarse fraction data identifies I 35 storms in the LT case and 94 storms in the HT case. Panel (b) is the plot of hurricane frequency through time that results from applying a 157-year sliding window to the sample-to-sample excursions in coarse fraction. In this method, each successive coarse fraction value is subtracted from the previous value and the $L T$ and $H T$ values are applied to the resulting positive excursions in order to identify storm events. The historically-derived LT and HT coarse fraction excursions ( 2.0 and I0.0, respectively) were based on the values associated with the I94I A.D. hurricane and the I894/I896 A.D. hurricanes, respectively. This method identifies 160 values exceeding the LT and 64 values exceeding the HT. Panel (c) is the storm frequency time series from previous figures. In this case, the raw data were first filtered to remove variability on frequencies lower than 30-I yrs-I. While the frequency filtering method ultimately identifies the most storms (I77 LT and $107 \mathrm{HT}$ ) by removing detection biases resulting from low-frequency changes in background sediment composition, the general congruence of all three storm frequency time series suggests that the major features of the record and the findings they support are not artifacts of how the data were processed. 


\section{References}

Anthes, R.A., Corell, R.W., Holland, G., Hurrell, J.W., MacCracken, M.C., Trenberth, K.E., 2006. Hurricanes and Global Warming: Potential Linkages and Consequences. Bulletin of the American Meteorological Society. 87, 623-628.

Bender, M.A., Knutson, T.R., Tuleya, R.E., Sirutis, J.J., Vecchi, G.A., Gerner, S.T., Held, I.M., 2010. Modeled impact of anthropogenic warming on the frequency of intense Atlantic hurricanes. Science. 327(5964), 454-458.

Blum, M.D., Sivers, A.E., Zayac, T., Goble, R.J., 2003. Middle Holocene sea level and evolution of the Gulf of Mexico coast. Transactions-Gulf Coast Association of Geological Societies. 53, 64-77.

Boldt, K.V., Lane, P., Woodruff, J.D., Donnelly, J.P., 2010. Calibrating a sedimentary record of overwash from Southeastern New England using modeled historic hurricane surges. Marine Geology. 275. pp. 127-139.

Case, R. A., 1986. Atlantic Hurricane Season of 1985. Monthly Weather Review. 114, 1390-1405.

Chang, E. K. M., Guo Y., 2007. Is the number of North Atlantic tropical cyclones significantly underestimated prior to the availability of satellite observations? Geophysical Research Letters. 34, L14801,doi:10.1029/2007GL030169.

Chen, K., McAneney, J., Cheung, K., 2009. Quantifying changes of wind speed distributions in the historical record of Atlantic tropical cyclones. Natural Hazards and Earth System Sciences. 9, 1749-1757.

Cohen, A., 2001. Hurricane tracking with chemistry: Exploring the coral archive. Workshop on Atlantic Basin paleohurricane reconstructions from high resolution records, March 25-27, 2001. Columbia, South Carolina, University of South Carolina.

Collins, E.S., Scott, D.B., Gayes, P.J., 1999. Hurricane records on the South Carolina coast: can they be detected in the sediment record? Quaternary International. 56. pp. 15-26.

Cooper, C.K., 1992. A preliminary case for the existence of hurricane alleys in the Gulf of Mexico. Proceedings of the $24^{\text {th }}$ annual offshore technology conference. OTC6831. OTC: Houston, TX. pp. 213-222.

Dean, W.E., 1974. Determination of carbonate and organic matter in calcareous sediments and sedimentary rocks by loss on ignition: comparison with other methods. Journal of Sedimentary Petrology. 44, 242-248.

de Rijk, S., 1995. Salinity control on the distribution of salt-marsh foraminifera (Great-Marshes, Massachusetts). Journal of Foraminiferal Research. 25, 156-166. 
de Rijk, S., Troelstra, S.R., 1997. Salt marsh foraminifera from the Great Marshes, Massachusetts: environmental controls. Palaeogeography, Palaeoclimatology, Palaeoecology. 130, 81-112.

Donnelly, J.P., S.S. Bryant, J. Butler, J. Dowling, L. Fan, N. Hausmann, P. Newby, B. Shuman, J. Stern, K. Westover, Webb III., T., 2001. A 700-year sedimentary record of intense hurricane landfalls in southern New England. Geological Society of America Bulletin. 113, 714-727.

Donnelly, J.P., S. Roll, M. Wengren, J. Butler, R. Lederer, Webb III, T., 2001. Sedimentary evidence of intense hurricane strikes from New Jersey. Geology. 29, 615-618.

Donnelly, J.P., J. Butler, S. Roll, Micah Wengren, Webb III, T., 2004. A backbarrier overwash record of intense storms from Brigantine, New Jersey. Marine Geology. 210, 107-121.

Donnelly, J.P., 2005. Evidence of Past Intense Tropical Cyclones from Backbarrier Salt Pond Sediments: A Case Study from Isla de Culebrita, Puerto Rico, USA. Journal of Coastal Research. SI42, 201-210.

Donnelly, J.P., Woodruff, J.D., 2007. Intense hurricane activity over the past 5,000 years controlled by El Niño and the West African monsoon. Nature. 447, 465-468.

Donnelly, J.P., Giosan, L., 2008. Tempestuous highs and lows in the Gulf of Mexico. Geology. 36(9), 751-752.

Elsner, J.B., Liu, K.B., Kocher, B.L., 2000. Spatial variations in major United States hurricane activity: Statistics and a physical mechanism. Journal of Climate 13, 2293-2305.

Elsner, J. B., 2003. Tracking hurricanes. Bulletin of the American Meteorological Society. 84, $353-356$.

Elsner, J.B., Kossin, J.P., Jagger T.H., 2008. The increasing intensity of the strongest tropical cyclones. Nature. 455, 92-95.

Emanuel, K.A., 2005. Increasing destructiveness of tropical cyclones over the past 30 years. Nature. 436, 686-688.

Emanuel, K.A., Sundararajan, R., William, J., 2008. Hurricanes and global warming: results from downscaling IPCC AR4 simulations. Bulletin of the American Meteorological Society. 89, 347-367.

Faure, G., 1986. Principles of Isotope Geology: Second Edition. John Wiley and Sons, U.S.A., pp. 374-377.

Frappier, A.B., Sahagian, D., Carpenter, S.J., Gonzalez, L.A., Frappier, B.R., 2007. Stalagmite stable isotope record of recent tropical cyclone events. Geology. 35(2). pp. 111-114. 
Ghil, M., Allen, M.R., Dettinger, M.D., Ide, K., Kondrashov, D., Mann, M.E., Robertson, A.W., Saunders, A., Tian, Y., Varadi, F., Yiou, P., 2002. Advanced Spectral Methods for Climatic Time Series. Review of Geophysics. 40(1), 1-1 - 1-4.

Goldenberg, S.B., Shapiro, L.J., 1996. Physical mechanisms for the association of El Niño and West African rainfall with Atlantic major hurricane activity. Journal of Climate. 9, 1169-1187.

Goldenberg, S.B., Landsea, C.W., Mestas-Nuñez, A.M., Gray, W.M., 2001. The recent increase in Atlantic hurricane activity: causes and implications. Science. 293, 474-479.

Gualdi, S., Scoccimarro, E., Navarra, A., 2008. Changes in tropical cyclone activity due to global warming: results from a high-resolution coupled general circulation model. Journal of Climate. 21, 5204-5228.

Hart, R., Maue, R., Watson, M., 2007. Estimating the atmospheric and SST memory of tropical cyclones through MPI anomaly evolution. Monthly Weather Review. 135, 3990-4005.

Hart, R.E., 2009. Tropical cyclones as winter's thieves or climate's puppets? Nature Geoscience, In review.

Hebert, P.J., 1976. Atlantic Hurricane Season of 1975. Monthly Weather Review. 104, 458-462.

Hetzinger, S., Pfeiffer, M., Dullo, W.-C., Keenlyside, N., Latif, M., Zinke, J., 2008. Caribbean coral tracks Atlantic multidecadal oscillation and past hurricane activity. Geology. 36(1), 11-14.

Hippensteel, S.P., Martin, R.E., 1999. Foraminifera as an indicator of overwash deposits, barrier island sediment supply, and barrier island evolution, Folly Island, South Carolina. Palaeogeography, Palaeoclimatology, Palaeoecology. 149, 115-125.

Hippensteel, S.P., Martin, R.E., 2000. Foraminifera as indicators of storm deposition: Implications for barrier island sediment supply and evolution, in Martin, R.E., ed., Environmental Micropaleontology: Dordrecht, Kluwer Press, p. 351-369.

Hippensteel, S.P., Martin, R.E., Harris, M.S., 2005. Discussion: Records of prehistoric hurricanes on the South Carolina Coast based on micropaleontological and sedimentological evidence, with comparison to other Atlantic Coast records. Geological Society of America Bulletin. 117, 250-256.

Hippensteel, S.P., 2008. Preservation potential of storm deposits in South Carolina back-barrier marshes. Journal of Coastal Research. 24(3), 594-601.

Ho, F.P., Tracey, R.J., 1975. Storm tide frequency analysis for the Gulf Coast of Florida from Cape San Blas to St. Petersburg Beach. NOAA Technical Memorandum NWS HYDRO-20. Office of Hydrology, Silver Spring, MD. 
Hodell, D. A., Brenner, M., Curtis, J. H., Medina-González, R., Ildefonso-Chan Can, E., AlbornazPat, A., Guilderson, T. P., 2005. Climate change on the Yucatan Peninsula during the Little Ice Age. Quaternary Research. 63, 109-121.

Holland, G. J., Webster, P.J., 2007. Heightened tropical cyclone activity in the North Atlantic: Natural variability or climate trend? Philosophical Transactions of the Royal Society of London. Ser. A. doi:10.1098/rsta.2007.2083.

Holland, G.J., 2007. Misuse of landfall as a proxy for Atlantic tropical cyclone activity. Eos Transactions. 88(36), 349-350.

Horton, B.P., Edwards, R.J., 2006. Quantifying Holocene sea-level change using intertidal foraminifera: lessons for the British Isles. Cushman Foundation for Foraminiferal Research, Special Publication, 40, 97 pp.

Hoyos, C. D., P. A. Agudelo, P. J. Webster, Curry, J.A., 2006. De-convolution of the factors contributing to the increase in global hurricane intensity. Science. 312, 94-97.

Huybers, P., 2010. "Multi-taper Spectral Analysis.” <

http://www.people.fas.harvard.edu/ phuybers/Mfiles/pmtmPH.m>.

Jagger, T.H., Elsner, J.B., 2008. Modeling tropical cyclone intensity with quantile regression. International Journal of Climatology. doi: 10.1002/joc. 1804.

Jarvinen, B.R., Neumann, C.J., Davis, M.A.S., 1984. A tropical cyclone data tape for the North Atlantic Basin, 1886-1983: Contents, limitations, and uses. NOAA Technical Memorandum NWS NHC 22, Coral Gables, Florida, 21 pp.

Javaux, E., Scott, D.B., 2003. Illustration of recent benthic foraminifera in Bermuda and remarks on species distribution. Palaeontologica electronica. 6 (1). Sept. 2003.

Jelesnianski, C.P., Chen, J., Shaffer W.A., 1992. SLOSH: Sea, Lake, and Overland Surges from Hurricanes. NOAA Technical Report NWS 48, April 1992, Silver Spring, Maryland.

Kindinger, J. L., Davis, J. B., Flocks, J. G., 1999. Geology and evolution of lakes in north-central Florida. Environmental Geology. 38, 301-321.

Knutson, T.R., Sirutis, J.J., Garner, S.T., Vecchi, G.A., Held, I.M., 2008. Simulated reduction in Atlantic hurricane frequency under twenty-first-century warming conditions. Nature Geoscience. doi:10.1038/ngeo202.

Koide, M., Bruland, K.W., Goldberg, E.D., 1973. $\mathrm{Th}^{228} / \mathrm{Th}^{232}$ and $\mathrm{Pb}^{210}$ geochronologies in marine and lake sediments. Geochimica et Cosmochimica Acta. 37, 1171-1188.

Kossin, J. P., K. R. Knapp, D. J. Vimont, R. J. Murnane, Harper, B.A., 2007. A globally consistent reanalysis of hurricane variability and trends. Geophysical Research Letters. 34, 
L04815, doi:10.1029/2006GL028836.

Kossin, J.P., Camargo, S.J., 2009. Hurricane track variability and secular potential intensity trends. Climatic Change Letters. 97, 329-337.

Lambert, W. J., Aharon, P., Rodriguez, A.B., 2003. An Assessment of the Late Holocene Record of Severe Storm Impacts from Lake Shelby, Alabama. Transactions-Gulf Coast Association of Geological Societies. 53. pp. 443.

Lambert, W.J., Aharon, P., Rodriguez, A.B., 2008. Catastrophic hurricane history revealed by organic geochemical proxies in coastal lake sediments: a case study of Lake Shelby, AL (USA). Journal of Paleolimnology. 39, 117-131.

Landsea, C.W., C. Anderson, N. Charles, G. Clark, J. Dunion, J. Fernández-Partagás, P. Hungerford, C. Neuman, Zimmer, M., 2004. The Atlantic hurricane database reanalysis project: documentation for 1851-1910 alterations and additions to the HURDAT database. In: Murnane, R. and Liu, K. (eds.), Hurricanes and Typhoons: Past Present and Future, New York: Columbia Press, pp. 177-221.

Landsea, C.W., Glenn, D.A., Bredemeyer, W., Chenoweth, M., Ellis, R., Gamache, J., Hufstetler, L., Mock, C., Perez, R., Prieto, R., 2008. A Re-Analysis of the 1911-1920 Atlantic Hurricane Database. Journal of Climate. 21(10), 2138-2168.

Landsea, C. W., 2007. Counting Atlantic tropical cyclones back to 1900. Eos Transactions. 88(18), 197-202.

Lane, E., 1986. Karst in Florida. Special Publication No. 29. Florida Geological Survey. 100 pp.

Liu, K.B., Fearn, M.L., 1993. Lake-sediment record of late Holocene hurricane activities from coastal Alabama. Geology 21, 793-796.

Liu, K.B., Fearn, M.L., 2000. Reconstruction of prehistoric landfall frequencies of catastrophic hurricanes in northwestern Florida from lake sediment records. Quaternary Research 54, 238-245.

Liu, K. B., Fearn, M.L., 2002. Lake sediment evidence of coastal geologic evolution and hurricane history from Western Lake, Florida: Reply to Otvos. Quaternary Research. 57, 429-431.

Ludlum, D. M., 1963. Early American Hurricanes. American Meteorological Society, Boston

Mann, M.E., Lees, J., 1996. Robust estimation of background noise and signal detection in climatic time series. Climatic Change. 33, 409-445.

Mann, M. E., Emanuel, K.A., 2006. Atlantic hurricane trends linked to climate change. Eos Transactions. 87(24), 233-235.

Mann, M.E., Emanuel, K.A., Holland, G.J., Webster, P.J., 2007. Atlantic tropical cyclones revisited. Eos Transactions. 88(36), 350-352. 
Mann, M.E., Woodruff, J.D., Donnelly, J.P., Zhang Z., 2009. Atlantic hurricanes and climate over the past 1500 years. Nature. 460, 880-885.

Miller, D.L., Mora, C.I., Grissino-Mayer, H.D., Mock, C.J., Uhle, M.E., Sharp, Z., 2006. Treering isotope records of tropical cyclone activity. Proceedings of the National Academy of Sciences. 103(39), 14294-14297.

Milliken, K.T., Anderson, J.B., Rodriguez, A.B., 2008. A new composite Holocene sea-level curve for the northern Gulf of Mexico." In Anderson, J.B. and A.B. Rodriguez, eds. "Response of upper Gulf Coast estuaries to Holocene climate change and sea level change. The Geological Society of America Special Paper 443, 1-11.

Morey, S.L., Baig, S., Bourassa, M.A., Duklovskoy, D.S., O’Brien, J.J., 2006. Remote forcing contribution to storm-induced sea level rise during Hurricane Dennis. Geophysical Research Letters. 33, L19603, doi:10.1029/2006GL027021.

Morton, R.A., Paine, J.G., Blum, M.D., 2000. Responses of stable bay-margin and barrier-island systems to Holocene sea-level highstands, western Gulf of Mexico. Journal of Sedimentary Research. 70, 478-490.

Moy, C.M., Seltzer, G.O., Rodbell, D., Anderson, D.M., 2002. Variability of E1 Nino/Southern Oscillation activity at millennial time scales during the Holocene epoch. Nature. 420(6912), 162165.

Nguetsop, V.F., Servant-Vildary, S., Servant M., 2004. Late Holocene climatic changes in West Africa, a high resolution diatom record from equatorial Cameroon. Quaternary Science Review. 23, 591-609.

NOAA., 2010. Tides and Currents. <http://tidesandcurrents.noaa.gov >.

NOAA,. 2010. Hurricane Research Division Re-Analysis Project. < http://www.aoml.noaa.gov/hrd/hurdat/Data_Storm.html>.

Nott, J., Hayne, M., 2001. High frequency of 'super-cyclones' along the Great Barrier Reef over the last 5000 years. Nature. 413, 508-512.

Nott, J., Haig, J., Neil, H., Gillieson, D., 2007. Greater frequency variability of landfalling tropical cyclones at centennial compared to seasonal and decadal scales. Earth and Planetary Science Letters. 255. pp. 367-372.

Nott, J., Smithers, S., Walsh, K., Rhodes, E., 2009. Sand beach ridges record 6000 year history of extreme tropical cyclone activity in northeastern Australia. Quaternary Science Reviews. 28, 1511-1520.

Otvos, E.G., 2001. Assumed Holocene highstands, Gulf of Mexico: basin issues of sedimentary 
and landform criteria: discussion. Journal of Sedimentary Research. 71(4), 645-647.

Pennington, W., Cambray, R.S., Fisher, E.M., 1973. Observations on Lake Sediments Using Fallout Cs-137 as a Tracer. Nature. 242, 324-326.

Percival, D.B., Walden, A.T., 1993. Spectral analysis for physical applications: multitaper and conventional univariate techniques. Cambridge University Press. pp. 256 \& 370.

Phleger, F.B., 1965. Living foraminifera from coastal marsh, southwestern Florida. Bol. Soc. Geology Mexicana. 28, 45-60.

Puri, H.S., Vernon, R.O., 1964. Summary of the geology of Florida and a guidebook to the classic exposures. Special Publication No. 5. Florida Geological Survey. 311 pp.

Reimer, P.J., Baillie, M.G.L., Bard, E., Bayliss, A., Beck, J.W., Blackwell, P.G., Bronk-Ramsey, C., Buck, C.E., Burr, G.S., Edwards, R.L., Friedrich, M., Grootes, P.M., Guilderson, T.P., Hajdas, I., Heaton, T.J., Hogg, A.G., Hughen, K.A., Kaiser, K.F., Kromer, B., McCormac, F.G., Manning, S.W., Reimer, R.W., Richards, D.A., Southon, J.R., Talamo, S., Turney, C.S.M., van der Plicht, J., Weyhenmeyer, C.E., 2009. IntCa109 and Marine09 radiocarbon age calibration curves, 0-50,000 years cal BP. Radiocarbon. 51(4), 1111-1150.

Robbins, J.A., Edgington, D.N., 1975. Determination of recent sedimentation rates in Lake Michigan using Pb-210 and Cs-137. Geochimica et Cosmochimica Acta. 39, 285-304.

Scileppi, E.M., Donnelly, J.P., 2007. Sedimentary evidence of hurricane strikes in western Long Island, New York. Geochemistry, Geophysics, Geosystems. 8(6), Q06011.

Scott, D.B., Medioli, F.S., 1980. Quantitative studies of marsh foraminiferal distributions in Nova Scotia: Implications for sea level studies. Cushman Foundation for Foraminiferal Research Special Publication 17, 58 p.

Scott, D.B., Suter, J., Kosters, E.C., 1991. Marsh foraminifera and arcellaceans of the lower Mississippi Delta: controls on spatial distributions. Micropaleontology. 37, 373-392.

Scott, D.B., Medioli, F.S., Schafer, C.T., 2001. Monitoring in coastal environments using foraminifera and thecamoebian indicators. Cambridge University Press, London. 175 p.

Scott, D.B., Collins, E.S., Gayes, P.T., Wright, E., 2003. Records of prehistoric hurricanes on the South Carolina coast based on micropaleontological and sedimentological evidence, with comparison to other Atlantic Coast records. Geological Society of America Bulletin. 115, 10271039 .

Sen Gupta, B.K., 1999. Foraminifera in marginal marine environments. In: B.K. Sen Gupta, Editor, Modern Foraminifera, Kluwer Academic Publishers, London. pp. 141-160.

Simms, A.R. Aryal, N., Yokoyama, Y., Matsuzuki, H, Dewitt, R., 2009. Insights on proposed 
mid-Holocene highstand along the northwestern Gulf of Mexico from the evolution of small coastal ponds. Journal of Sedimentary Research. 79(10), 757-772.

Sinclair, W.C., Stewart, J.W., 1985. Sinkhole type, development, and distribution in Florida. USGS. Map Series No. 110. Tallahassee, Florida.

Stapor, F.W., Mathews, T.D., Lindfors-Kearns, F.E., 1991. Barrier-island progradation and Holocene sea-level history in southwest Florida. Journal of Coastal Research. 7, 815-838.

Tanner, W.F., 1992. 3000 years of sea level change. Bulletin of the American Meteorological Society. 73, 297-304.

Trenberth, K. E., Shea, D.J., 2006. Atlantic hurricanes and natural variability in 2005.

Geophysical Research Letters. 33, L12704, doi:10.1029/2006GL026894.

Törnqvist, T. E., Gonzalez, J. L., Newsom, L. A., van der Borg, K., de Jong, A. F. M., Kurnik, C.W., 2004. Deciphering Holocene sea-level history on the US Gulf Coast: A high-resolution record from the Mississippi Delta. Geological Society of America Bulletin. 116(7-8), 1026-1039.

Ulm, K., 1990. A simple method to calculate the confidence interval of a standardized mortality ratio. American Journal of Epidemiology. 131(2), 373-375.

USEPA., 1999. Ecological condition of estuaries in the Gulf of Mexico. EPA 620-R-98-004. U.S. Environmental Protection Agency, Office of Research and Development, National Health and Environmental Effects Research Laboratory, Gulf Ecology Division, Gulf Breeze, Florida. 80 pp.

Vickery, P. J., Skerlj, P.F., Twisdale, L.A., 2000. Simulation of hurricane risk in the U. S. using empirical track model. Journal of Structural Engineering. 126, 1222-1237.

Wallace, D.J., Anderson, J.B., 2010. Evidence of similar probability of intense hurricane strikes for the Gulf of Mexico over the late Holocene. Geology. 38(6). pp. 511-514.

Watts, W. A., Hansen, B. C. S., Grimm, E. C., 1992. Camel Lake: A 40,000-yr record of vegetational and forest history from northwest Florida. Ecology. 73, 1056-1066.

Watts, W.A., Hansen, B.C.S., 1994. Pre-Holocene and Holocene pollen records of vegetation history from the Florida peninsula and their climatic implications. Palaeogeography, Palaeoclimatology, Palaeoecology. 109, 163-176.

Webster, P.J., Holland, G.J, Curry, J.A., Chang, H.R., 2005. Changes in tropical cyclone number, duration, and intensity, in warming environment. Science. 309, 1844-1846.

Williams, H.F.L., 2010. Storm surge deposition by Hurricane Ike on the McFaddin National Wildlife Refuge, Texas: Implications for paleotempestology studies. Journal of Foraminiferal Research. 40(3). pp. 210-219. 
Woodruff, J.D., Donnelly, J.P., Emanuel, K.A., Lane, P., 2008. Assessing sedimentary records of paleohurricane activity using modeled hurricane climatology. Geochemistry, Geophysics, Geosystems. 9(9). Q09V10.

Woodruff, J.D., Donnelly, J.P., Mohrig, D., Geyer, W.R., 2008. Reconstructing relative flooding intensities responsible for hurricane-induced deposits from Laguna Playa Grande, Vieques, Puerto Rico. Geology. 36(5), 391-394.

Wright, E.E., Hine, A.C., Goodbred, S.L., Locker, S.D., 2005. The Effect of Sea-Level and Climate Change on the Development of a Mixed Siliciclastic-Carbonate, Deltaic Coastline: Suwannee River, Florida, USA. Journal of Sedimentary Research. 75(4), 621-635.

Zarikian, C.A., Swart, P.K., Gifford, J.A., Blackwelder, P.L., 2005. Holocene paleohydrology of Little Salt Spring, Florida, based on ostracod assemblages and stable isotopes. Palaeogeography, Palaeoclimatology, Palaeoecology. 225, 134-156.

Zhao M., Held, I.M., Lin, S.J., Vecchi, G.A., 2009. Simulations of global hurricane climatology, interannual variability, and response to global warming using a 50km resolution GCM. Journal of Climate: In Press. doi: 10.1175/2009JCLI3049.1 